Ali, Majd; Ajib, Salman:

Energy analysis and modeling study of combined activated carbonsilica gel/methanol adsorption ice production system

Original published in:

Global Journal of Energy Technology Research Updates. - Windsor CT : Avanti Publishers.Com. - 3 (2016), 1, p. 65-86.

Original published: March 01, 2016

ISSN: 2409-5818

DOI: 10.15377/2409-5818.2015.03.01.1

[ Visited: May 16, 2019]

This work is licensed under a Creative Commons AttributionNonCommercial 3.0 Unported license.

To view a copy of this license, visit http://creativecommons.org/licenses/BY-NC/3.0 


\title{
Energy Analysis and Modeling Study of Combined Activated Carbon-Silica Gel/Methanol Adsorption Ice Production System
}

\author{
Majd Ali ${ }^{1, *}$ and Salman Ajib² \\ ${ }^{1}$ IImenau University of Technology, Faculty of Mechanical Engineering, Institute of Thermodynamics and \\ Fluid Dynamics, Helmholzring 1, 98693 Ilmenau, Germany \\ ${ }^{2}$ Hochschule Ostwestfalen-Lippe, Department of Renewable Energies and Decentralized Energy Supplying, \\ Wilhelmshöhe 44, D 37671 Höxter, Germany
}

\begin{abstract}
In this article, the transient modelling for a new construction of the Adsorption cold production was investigated. This system, named in this work the combined Adsorption Ice Production system (com-AlP system), was filled by both silica gel (SG) and activated carbon (AC) together in one adsorption reactor as the adsorbent and methanol as the adsorbate and refrigerant.

A fined-tube heat exchanger was designed (named combined adsorption reactor) in order to contain two different adsorbents in the adsorption reactor and increase the heat transfer ability between the particles of adsorbents and heat exchanger fins. As a result the input energy required from the external heat source is saved and the coefficient of performance COP of the com-AIP system is improved. The mass flow rate of refrigerant $\dot{\mathrm{m}}_{\text {ref }}$ increases and consequently, the refrigeration energy $Q_{e}$ rises too. A cycle simulation computer program of this innovative bed was developed to analyze the refrigeration energy and COP variations by varying heat transfer fluid (hot, cooling and chilled water) inlet temperatures and adsorption/desorption cycle time. The transient behavior of heat and mass transfer fluids has been also studied. Under the standard test conditions of $100{ }^{\circ} \mathrm{C}$ hot water, $24{ }^{\circ} \mathrm{C}$ cooling water, and $15^{\circ} \mathrm{C}$ chilled water inlet temperatures, the simulation results showed that the amount of the ice produced per cycle of $5.34 \mathrm{~kg}$ and $0.73 \mathrm{COP}$ can be achieved from the com-AIP system. It was found that the system performance is very much sensitive to the mass flow rate of the refrigerant. The cycle time of the system is not dependent on the amount of the adsorbents but is strongly dependent on driven temperature of heat exchange fluid and the design of the heat exchanger.

The com- adsorption reactor allows using the advantages of physical properties of both adsorbents SG and AC. Consequently, this innovative com-AIP system utilizes effectively low-temperature heat sources of temperature between 65 and $100^{\circ} \mathrm{C}$, because of the inferior thermodynamic properties of methanol and the low regeneration temperature from silica gel and activated carbon as adsorbents. This strategy (com-AlP system) is completely different from the conventional adsorption reactors, which are filled with one adsorbent in one bed or in two beds.
\end{abstract}

Keywords: Adsorption refrigeration machine, combined adsorption ice production (AIP) system, two different adsorbents (activated carbon and silica gel), one adsorption reactor, thermal analysis.

\section{INTRODUCTION}

There is a widely increasing need to develop the refrigeration technology by looking for alternative technologies. In recent years the adsorption refrigeration technology, called Green Refrigeration Technology, has been attracting more and more attention due to its advantages. It is energy-efficient and eco- friendly alternative to conventional systems such as electrical driven air-conditioning and refrigeration systems [1].

The adsorption refrigeration systems don't have to use ozone-depleting chlorofluorocarbons (CFCs) and don't need electricity or fossil fuels as driving sources, because adsorption cycles possess the advantage of employing natural and low global warming potential (GWP) refrigerants (water, methanol, ethanol, etc.). In

\footnotetext{
*Address correspondence to this author at the Ilmenau University of Technology, Faculty of Mechanical Engineering, Institute of Thermodynamics and Fluid Dynamics, Helmholzring 1, 98693 Ilmenau, Germany;

Tel: +49 (0) 5271-3910634; E-mails: majd.ali@tu-ilmenau.de; salman.ajib@hs-owl.de
}

addition, the adsorption systems could be driven by low-grade energy such as industry waste heat or solar energy [2-4].

The idea of these devices is the reversible physical sorption of a vapor on the surface of a porous solid (desorption of the refrigerant when exposed to heat and adsorption of it during cooling) [5-7]. Many researchers have been interested in the study of the adsorption cooling system both numerically and experimentally with the different working pairs of adsorbent-adsorbate. The popular typical working pairs are silica gel-water [8], silica gel-methanol [9], zeolitewater [10], activated carbon-ammonia [11], activated carbon-methanol [12], inorganic salt-ammonia, etc. Some studies have introduced the composite adsorbents to reduce the maximum temperature of adsorption cooling system [13]. The effectiveness of adsorption cooling systems using the different working pairs were investigated and assessed [14, 15]. These studies gave more realistic performance comparing to ideal cooling cycle performance. The adsorption 
working pairs used don't have ideal characteristics and although the physical properties of the sorption materials are limited, most of the published studies on the adsorption cold systems utilized one adsorbent in their adsorbent beds to simulate the system and to enhance its performance.

Activated carbon AC with methanol as a working pair is broadly used in adsorption refrigeration systems due to the high adsorption/desorption concentration $X\left[\mathrm{~kg}_{\text {meth }} / \mathrm{kg}_{\mathrm{AC}}\right]$, which reaches 0.45 and low desorption heat, which is about $1800-2000$ [kJ/kg]. Moreover, adsorbate uptake capacity of activated carbon is more than that of silica gel. The other important factor is density of the sorption material which affects the volume of adsorption reactor. Density of activated carbon is about $500 \mathrm{~kg} / \mathrm{m}^{3}$, whereas density of silica gel is about $750 \mathrm{~kg} / \mathrm{m}^{3}$ therefore, the amount of activated carbon is smaller than the amount of silica gel inside the same volume of adsorption reactor [3]. The system of activated carbon/methanol and silica gel/methanol need low grade heat source [16, 17]. On the other hand, methanol operates at sub atmospheric pressure; the low-pressure system is suitable to utilize the adsorption cold system as icemaker [18].

The adsorption refrigeration system in this article is developed using a new heat exchanger design which is filled by two different sorption materials together (silica gel and activated carbon) and one refrigerant (methanol) in the same adsorption reactor (chamber), named in this work com- adsorption reactor (com-bed), to improve its heat and mass transfer performance and changing the operating cycle.

This research presents a simulation of activated carbon-/silica gel-methanol finned tube adsorption reactor, a main component of the adsorption cooling system, and a comparison of com-AIP system with both silica gel/methanol and activated carbon/methanol adsorption cold systems to show the importance of this technology under the same operating conditions. Future works will focus on enhancing the coefficient of performance COP and saving of the required input heat by increasing the mass flow rate of refrigerant $\dot{m}_{\text {ref }}$ to achieve higher performance in terms of refrigeration capacity. Moreover, the impact of amounts of methanol desorbed $m_{\text {des }}$ adsorbed $m_{\text {ads }}$ and the desorption temperature inside the com-adsorption reactor on the performance and on the amount of produced ice $m_{\text {ice }}$ are considered.

\section{THERMODYNAMIC CYCLE OF THE COM-AIP SYSTEM}

The Adsorption Ice Production (AIP) system is similar to the basic vapor compression refrigeration machines except that the power compressor is replaced by a thermally driven compressor which is the adsorption reactor [19]. The adsorption reactor is composed of a solid medium that has affinity to physically adsorb and desorb the refrigerant vapor. In the present study a novel strategy of com-adsorption reactor is proposed to reduce the consumption of the needed driving energy and to enhance the COP. The schematic diagram of com-bed Adsorption Ice Maker system is shown in Figure 1.

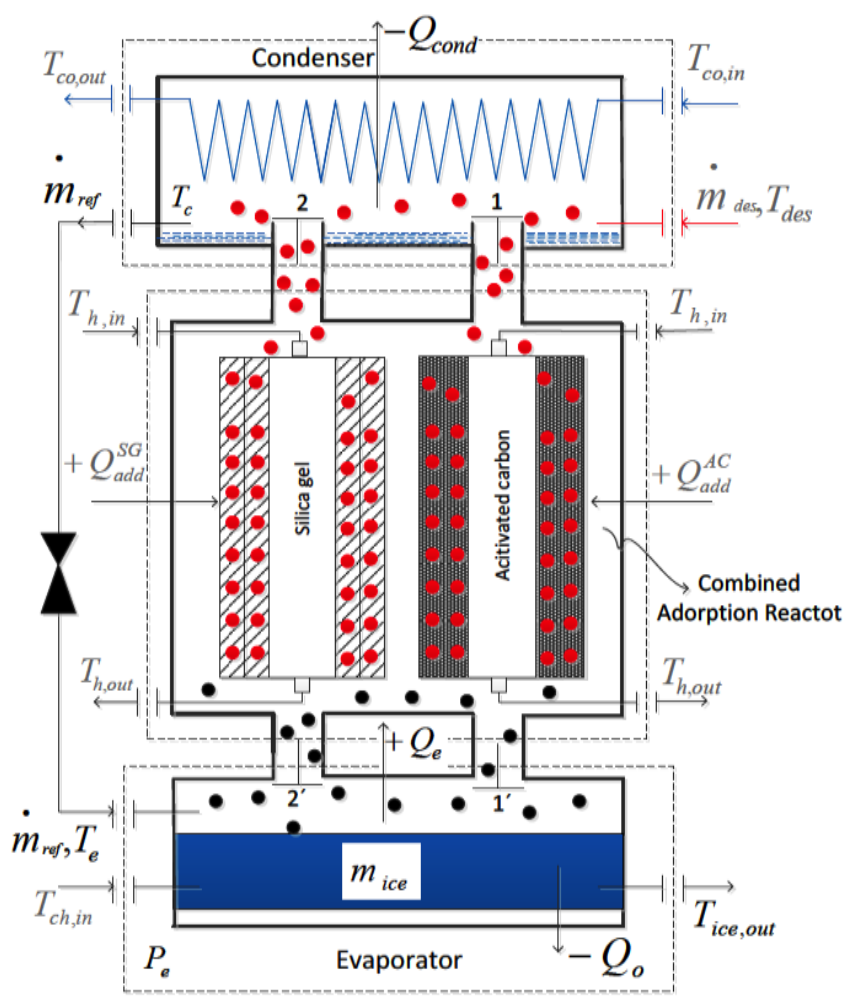

Figure 1: Schematic diagram of com- AIP system.

This suggested strategy is completely different from the conventional adsorption reactor which works using one working pair of adsorbent/refrigerant. Its working principle will be explained in the following section.

The other main components of the system studied are a condenser, an evaporator, a throttling device and 4 one-way control valves. This components of the system studied are shown also in Figure 1.

The basic adsorption refrigeration thermodynamic cycle is illustrated on the conceptual Clapeyron diagram, Figure 2. The cycle of the com-AIP system consists mainly of these processes: 


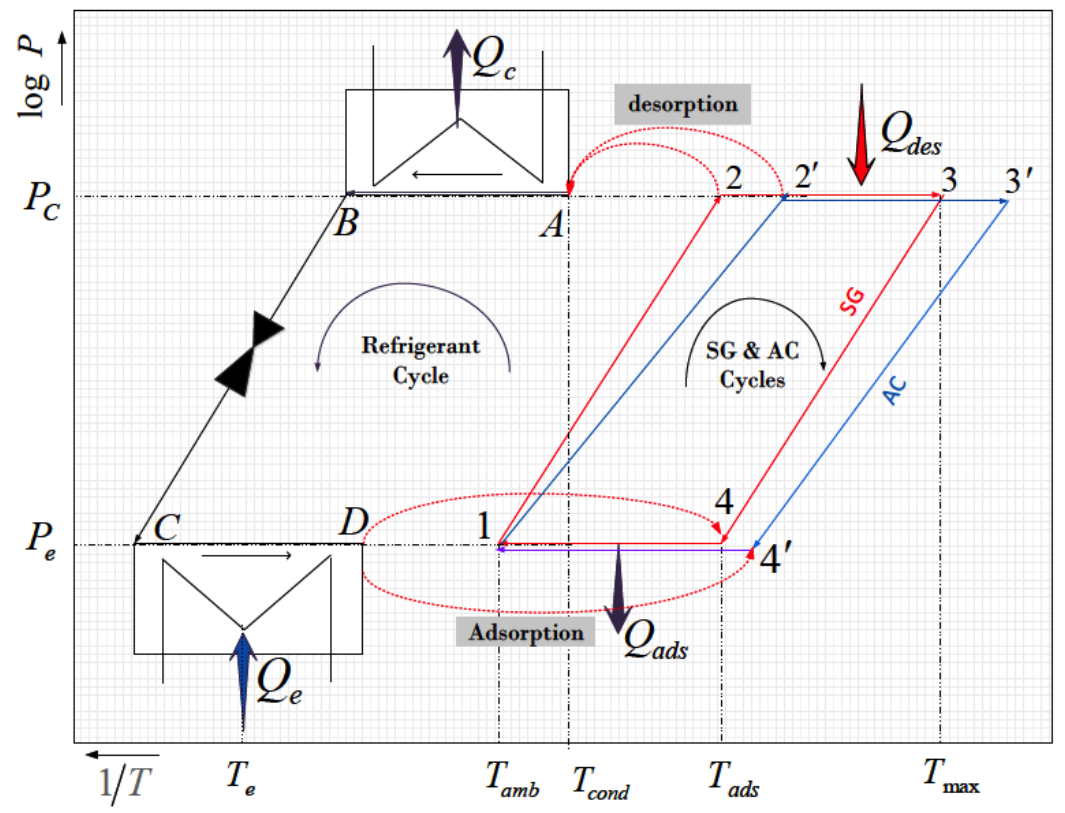

Figure 2: Clapeyron diagram for the basic Adsorption Ice Production thermodynamic cycle.

- $\quad 1 \rightarrow 2$ Isosteric heating and pressurization process at the constant higher concentration of the silica gel particles in the com-adsorption reactor.

- $\quad 1 \rightarrow 2^{\wedge}$ Isosteric heating and pressurization process at the constant higher concentration of the activated carbon particles in the comadsorption reactor.

- $\quad 2 \rightarrow 3$ Isobaric heating and desorption process from the silica gel particles.

- $\quad 2^{\prime} \rightarrow 3^{`}$ Isobaric heating and desorption process from the activated carbon particles.

- $\quad 3 \rightarrow 4$ Isosteric cooling and depressurization process at the constant lower concentration of silica gel adsorbent.
- $\quad 3^{`} \rightarrow 4^{\prime}$ Isosteric cooling and depressurization process at the constant lower concentration of activated carbon particles.

- $\quad 4 \rightarrow 1$ Isobaric cooling and adsorption process for the SG-adsorbent.

- $\quad 4 \rightarrow 1$ Isobaric cooling and adsorption process for the AC-adsorbent.

- $\quad \mathrm{A} \rightarrow \mathrm{B}$ condensation process at constant condenser pressure.

- $\quad \mathrm{C} \rightarrow \mathrm{D}$ evaporation process at constant evaporator pressure.

\section{WORKING PRINCIPLE OF COM- AIP SYSTEM}

To complete a full cycle for the proposed system, the whole cycle of the com-AIP system can be divided into 7 phases $A, B, C, D, E, F, G$ and $H$, shown Table 1.

Table 1: The States of Values in Operation and Working Processes of the Com- AIP System

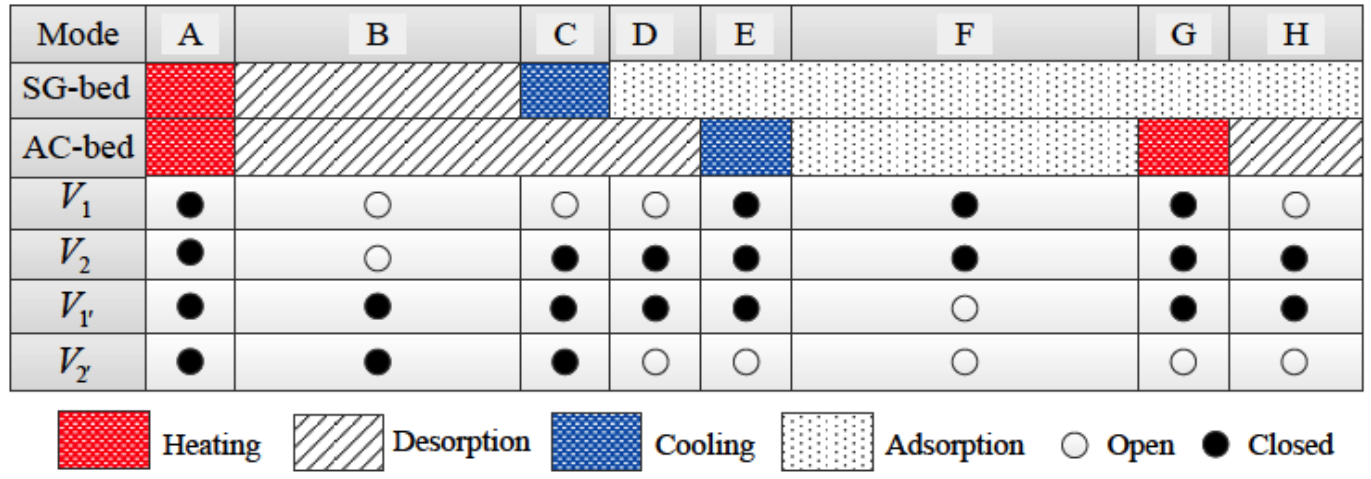


In the phase $A$ the com-adsorption reactor works in the isosteric pre-heating process. Hot water flows into SG-bed and AC-bed. The both beds are heated up by the hot water from a driving heat source. When the pressure of both beds are nearly equal to the pressure of condenser, both the AC-bed and the SG-bed are connected to the condenser in order to start the desorption process.

In the phase $\mathrm{B}$ the com-adsorption reactor works in the isobaric desorption process. The desorptioncondensation process takes place at the condenser pressure. In this mode only SG- desorber is heated up to the end desorption temperature $T_{\text {des, max }}$ by the heat input $\mathrm{Q}_{\text {des }}^{S G}$ provided by the driving heat source. The resulting refrigerant (methanol vapor) from SG-bed is cooled down by the temperature $T_{\text {cond }}$ in the condenser by the cooling water. The cooling water flows through the condenser and carries away the heat of condensation $Q_{\text {cond }}$. The condensate passes through expansion device into the evaporator. In this mode the methanol vapor desorbed from SG- particles helps to heat up the AC-bed. Consequently the heating energy is saved and COP is improved.
In the phase $C$ the SG-bed is in the isostericprecooling process and the AC-bed is still in the desorption process. During Pre -cooling process the SG-bed is isolated from the evaporator and the condenser. The operating states of the valves are shown in Table 1. The cooling water is supplied to the SG-bed for short time $\mathrm{t}_{\text {cooling }}^{\text {SG }}$ and is cooled down to the adsorption temperature.

In the phase $D$ while the SG-bed begins the adsorption process, the AC-bed is still in the desorption process. The SG-bed is at the start position of adsorption-evaporation process and AC-bed is at the end position of desorption-condensation process. The AC-desorber is heated up to the end desorption temperature by the heat input $\mathrm{Q}_{\text {des }}^{A C}$ provided by the driving heat source. This time the AC-bed is isolated from evaporator and condenser and is connected with cooling water. The SG-bed is connected with the evaporator in order to start the adsorption process.

In The phase $E$ the AC-bed begins the pre-cooling process and the SG-bed works as an adsorber. Cooling water is supplied to the AC-bed for short time $\mathrm{t}_{\text {cooling }}^{A C}$.
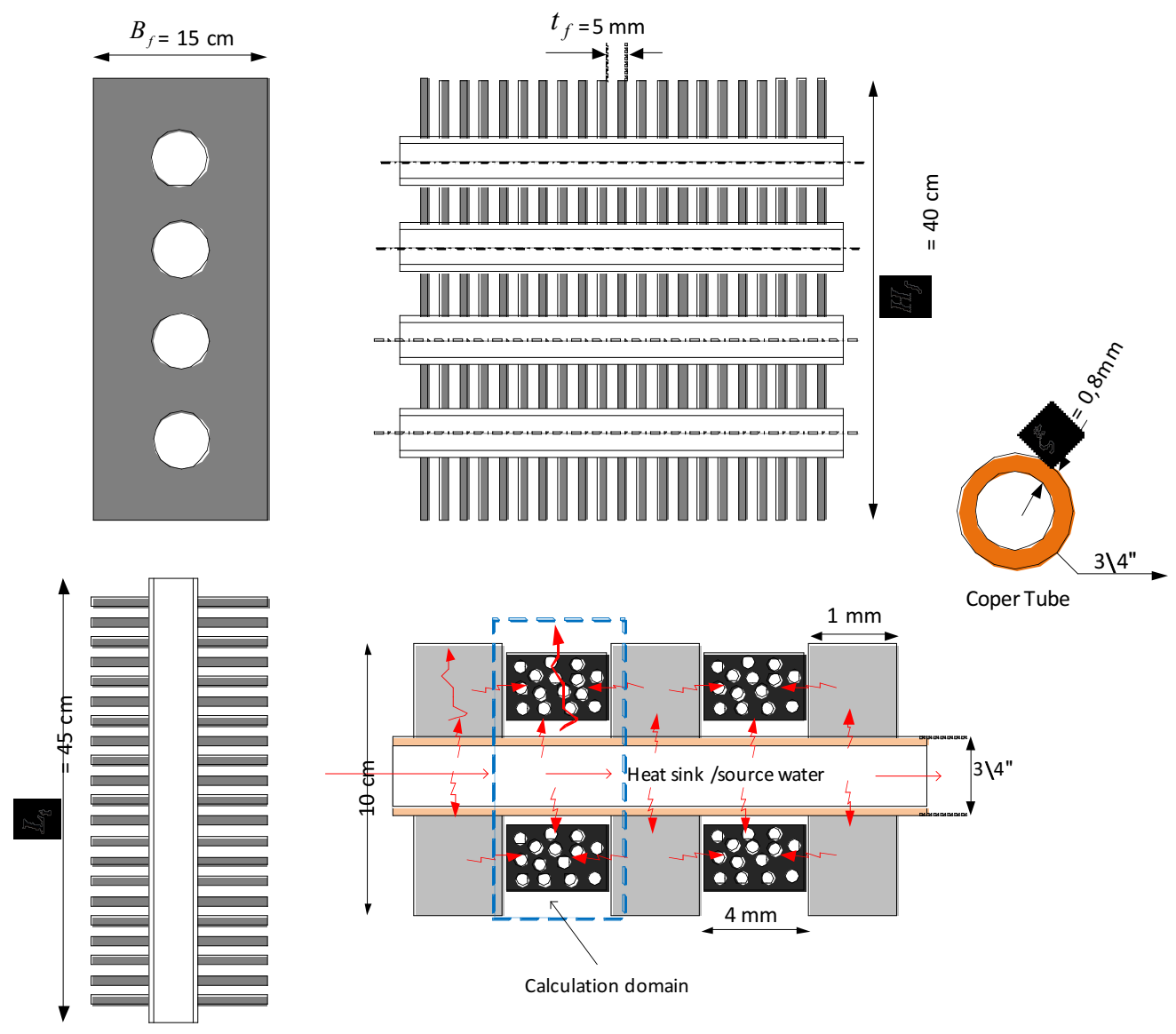

Figure 3: Schematic diagram for the rectangular finned tube adsorption reactor. 
In phase F, Both the SG-bed and AC-bed work as an adsorber. Because of the adsorption speed, the concentration level of $\mathrm{AC}$-adsorber reaches in nearly equilibrium faster than the concentration level of SGadsorber. In this mode the AC-adsorber reaches at the end position of adsorption-evaporation process, which is the last process for the AC-bed.

In phase $G$, the pre-heating process for AC-bed starts and the SG-bed works as adsorber.

In phase $\mathrm{H}$ the $\mathrm{AC}$-bed works as a desorber and SG-bed works as an adsorber. In this mode the SGadsorber is at the end position of adsorptionevaporation process, which is the last process for the SG-bed. After this mode the SG-cycle will return to its initial position.

\section{GEOMETRY MODEL PARAMETERS OF FINNED TUBE FOR COM-ADSORPTION REACTOR}

Figure 3 shows the schematic view of the finned tube heat exchanger developed in this study. It mainly consists of:

1. Four tubes of copper having inner diameter 17.3 [mm] and length $450[\mathrm{~mm}]$;

2. Fins of aluminum characterized by fin height $\mathrm{Hf}=40[\mathrm{~cm}]$, fin thickness $\mathrm{s}=1[\mathrm{~mm}]$ and fin pitch $\mathrm{t}_{\mathrm{f}}=4[\mathrm{~mm}] ;$

3. Activated carbon AC of type Maxsorb packed between the fins of two tubes and silica gel SG packed between the fins of another two tubes.

4. Mesh sheet covering the material of com-heat exchanger.

This com-heat exchanger is composed of flat tube with rectangular fins. There are 4 tube horizontally and 90 fins vertically arranged adsorption heat exchanger in all, between $3.9 \mathrm{~kg}$ silica gel and $3.3 \mathrm{~kg}$ activated carbon are employed which they are taken as same diameter $(\phi 1.15 \mathrm{~mm})$. This com-heat exchanger is used as desorber during desorption cycles and as an adsorber during adsorption cycles.

The characteristics of the find -tube heat exchanger used is listed in Table 2.

The design criteria of this innovative bed are almost similar to that of the two-bed chiller. However, in the proposed design, it needs no extra piping, which connects the bed with condenser and evaporator
Table 2: Characteristics of the Fined -Tube Combined Heat Exchanger

\begin{tabular}{|c|c|c|}
\hline Parameter & Value & Unit \\
\hline \hline Dimension & $450 \times 320 \times 200$ & {$[\mathrm{~mm}]$} \\
\hline Number of flat tube & 4 & {$[-]$} \\
\hline Tube diameter & 17.3 & {$[\mathrm{~mm}]$} \\
\hline Tube thickness $\zeta$ & 0.8 & {$[\mathrm{~mm}]$} \\
\hline Number of fins & 90 & {$[-]$} \\
\hline Fin width $\left(\mathrm{B}_{\mathrm{f}}\right)$ & 150 & {$[\mathrm{~mm}]$} \\
\hline Fin pitch $\left(\mathrm{t}_{\mathrm{f}}\right)$ & 4 & {$[\mathrm{~mm}]$} \\
\hline Heat transfer area $(A)$ & 5.34 & {$\left[\mathrm{~m}^{2}\right]$} \\
\hline Heat transfer coefficient $(\mathrm{U})$ & $4734 / 4915^{*}$ & {$\left[\mathrm{~W} / \mathrm{m}^{2} . \mathrm{K}\right]$} \\
\hline
\end{tabular}

* $U=4915\left[\mathrm{~W} / \mathrm{m}^{2} . \mathrm{K}\right]$ in case of the AC-bed and $\mathrm{U}=4915\left[\mathrm{~W} / \mathrm{m}^{2} . \mathrm{K}\right]$ in case of the SG-bed.

during desorption and adsorption. Instead of a two-bed system as usually installed in the commercially available adsorption chiller, only one com-adsorption reactor is used for this AIP system here, but it is packed with two different adsorbents. The activated carbon bed and silica gel bed are taken as same size. By means of this kind of design, the construction of the system can be simplified, the adsorbate concentration is increased and the dimension of adsorption reactor is diminished, hence mass flow rate of the refrigerant is increased and cooling power improved.

\section{MATHEMATICAL FORMULATION THERMODYNAMIC ANALYSIS APPROACH}

AND

A schematic of the com-adsorption reactor is shown in Figure 3. The modelling of this heat exchanger involves heat and mass conversation equations for the adsorbent particles of both SG and AC, the adsorbate refrigerant (methanol), the heat exchanger fluid (water) and the metallic components of the reactor (the metal tubes and the fins). The following assumptions are utilized:

- The average granules diameters of adsorbents $S G$ and $A C$ are similar.

- The temperature of refrigerant and adsorbents at the same point is the same.

- $\quad$ The adsorbed phase is considered as a liquid and the vapor methanol behaves as an ideal gas.

- The thermal resistance between the metal tube and the adsorbents is neglected. 
- The desorption and adsorption occur in the $X_{0}=\rho_{\text {adsorbate }}(T) \cdot V_{0}$ vapor phase of methanol.

The variation of temperature in the adsorption reactor and inside the tubes occurs in the redial direction only.

\subsection{Adsorption and Desorption Equations}

The uptake of the refrigerant $X[\mathrm{~kg} / \mathrm{kg}]$ by the adsorbent particles depends upon the pressure and the temperature of the adsorbate. The maximum value $X_{\max }$ is defined by the ambient temperature and evaporator pressure $X_{\max }=f\left(T_{\text {amb }}, P_{\text {evap }}\right)$. The adsorption and desorption concentrations $X$ are usually determined by Dubinin-Astakhov equation [20, 21]:

$\mathrm{X}_{(\mathrm{T}, \mathrm{P})}=\mathrm{X}_{0} \exp \left\{-\mathrm{D} \cdot\left[\mathrm{T} \cdot \ln \left(\frac{\mathrm{P}_{\mathrm{sat}}}{\mathrm{P}}\right)\right]^{\mathrm{n}}\right\}$

$\mathrm{X}_{\left(\mathrm{T}, \mathrm{T}_{\mathrm{sat}}\right)}=\mathrm{X}_{0} \exp \left\{-\mathrm{K} \cdot\left[\left(\frac{\mathrm{T}}{\mathrm{T}_{\mathrm{sat}}}-1\right)\right]^{\mathrm{n}}\right\}$

The initial adsorption concentration $\mathrm{X}_{0}$ depends on the adsorbate density $\rho_{a}(T)$ and is related to the maximum adsorption capacity by this equation: where $V_{0}$ is the maximum adsorption capacity $\left[\mathrm{m}^{3} / \mathrm{kg}\right.$ ]. $\mathrm{D}, \mathrm{K}$ and $\mathrm{n}$ are constants which can be determined experimentally depending on the adsorbate / adsorbent pair.

$\mathrm{P}_{\text {sat }}(T)$ and $\mathrm{P}_{\text {sat }}(T)$ are saturation pressure and temperature corresponding to the reactor temperature. The relation between the pressure and temperature during the isostericpre-heating and pre-cooling processes at steady state conditions is described by following equations:

$\mathrm{P}=\mathrm{P}_{\mathrm{sat}}(\mathrm{T}) \cdot \exp \left\{\frac{-1}{\mathrm{~T}}\left[\frac{1}{\mathrm{D}} \ln \left(\frac{\mathrm{X}_{0}}{\mathrm{X}}\right)\right]^{1 / \mathrm{n}}\right\}$

$\mathrm{T}=\mathrm{T}_{\mathrm{sat}} \cdot \exp \left\{1+\left[\frac{1}{\mathrm{~K}} \ln \left(\frac{\mathrm{X}_{0}}{\mathrm{X}}\right)\right]^{1 / \mathrm{n}}\right\}$

For a given evaporator temperature $\mathrm{T}_{\text {evap, the }}$ corresponding evaporator pressure, $P_{\text {evap }}$ is the saturation pressure of the refrigerant vapor $\mathrm{P}_{\text {sat }}\left(\mathrm{T}_{\text {evap }}\right)=$ $P_{\text {evap }}$ corresponding to $T_{\text {evap. }}$.

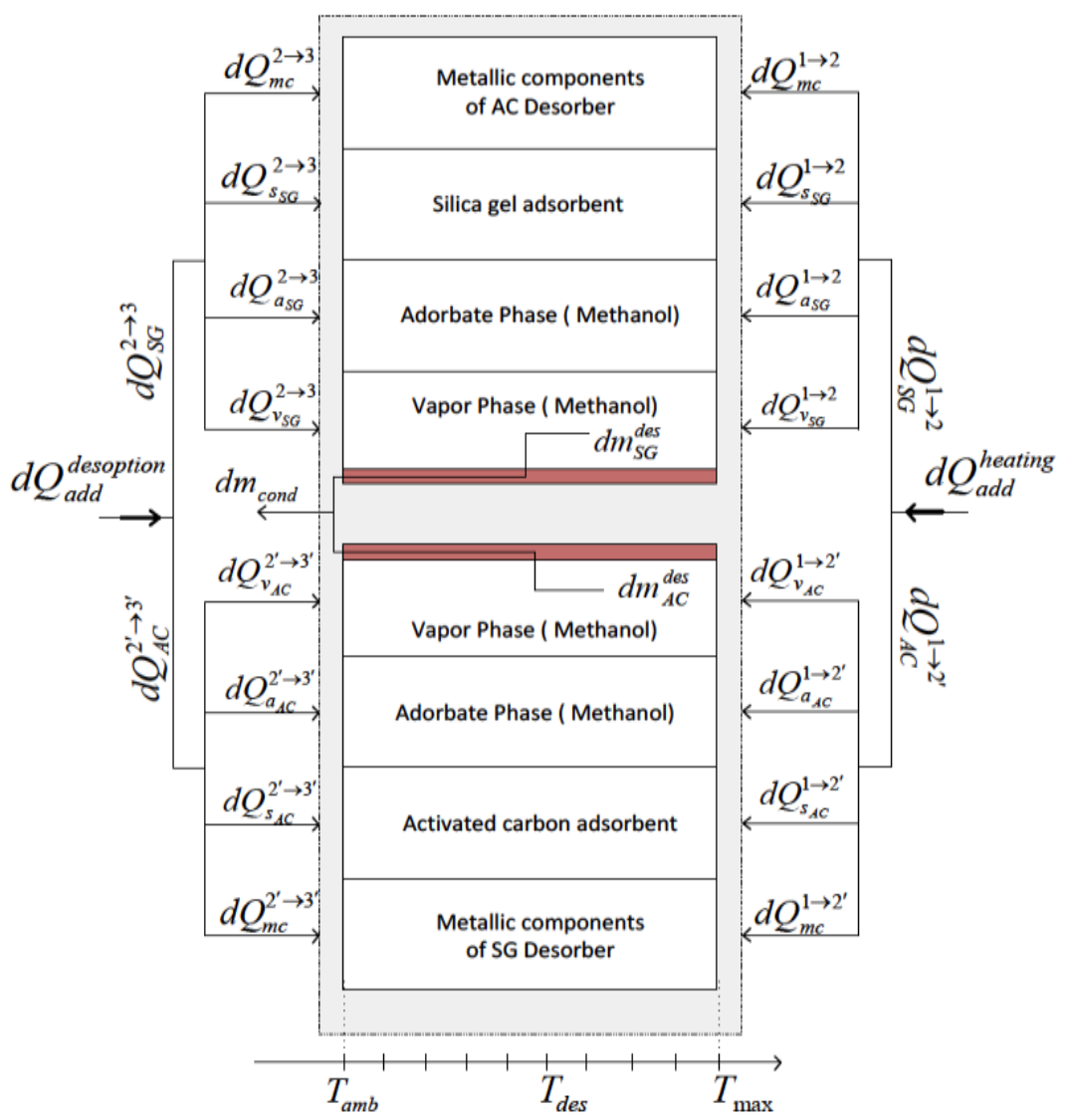

Figure 4: Energy flow diagram for the com-adsorption reactor during the isosteric and isobaric heating processes. 
According to equations (4) or (5) the processes cycle of AIP system can be displayed very well in (P-T) diagram, Figure 2. In this diagram the processes are plotted as two trapeziums. The first trapezium for SGbed is plotted between the isosteres $X_{\max }^{S G}$ and $X_{\min }^{S G}$ and the iso bares $P_{\text {cond }}$ and $P_{\text {evap }}$. Another trapezium for $A C$ bed, that is bigger than the first is too plotted at the same diagram with different values of $X_{\max }^{A C}$ and $X_{\min }^{A C}$ and with same evaporator and condenser pressure.

The kinetics of sorption $d X / d t$ is assumed to be governed by a linear driving force (LDF) model that could be used to describe internal mass transfer limitations with little error [22, 23, 24]. The term of the model is given by:

$$
\frac{\mathrm{dX}}{\mathrm{dt}}=\frac{11 \cdot \mathrm{D}_{0}}{\mathrm{r}_{\mathrm{P}}^{2}} \cdot \mathrm{e}^{\left(-\mathrm{E}_{\mathrm{a}} / \mathrm{R} \cdot \mathrm{T}\right)} \cdot\left(\mathrm{X}_{\mathrm{eq}}-\mathrm{X}\right)
$$

Where $X_{e q}$ is the equilibrium concentration at the corresponding pressure and temperature that is calculated by Dubinin-Astakhov Eq. (1) and X represents the actual concentration of the adsorbate.

\subsection{Isostatic Heating and Pressurization Process}

The input energy required by the com-adsorption reactor metallic components, the porous adsorbent media ( $S G$ and $A C$ ), the adsorbate phase (methanol) and the refrigerant vapor phase is shown in Figure 4. In the isosteric heating the com-adsorption reactor which is filled with silica gel and activated carbon particles is preheated at two constant highest isostere lines, because the uptake of the refrigerant for $S G$ and $A C$ particles has different values.

In this process, the methanol concentration in the heat exchanger remains constant. The added energy $Q_{\text {heating }}^{\text {add }}$ during the preheating process of the comadsorption reactor is utilized to cause sensible heating of the adsorption reactor constituents. The isosteric heat added is expressed as:

$$
\begin{aligned}
& \mathrm{dQ}_{\text {heating }}^{\text {add }}=\mathrm{dQ}_{1 \rightarrow 2}^{\mathrm{SG}}+\mathrm{dQ}_{1 \rightarrow 2}^{\mathrm{AC}}, \\
& \mathrm{dQ}_{1 \rightarrow 2}^{\mathrm{SG}}=\mathrm{dQ}_{\mathrm{mc}}^{\mathrm{SG}}+\mathrm{dQ}_{\text {sorbent }}^{\mathrm{SG}}+\mathrm{dQ}_{\text {adsorbat }}^{\mathrm{SG}}+\mathrm{dQ}_{\text {vapor }}^{\mathrm{SG}} \\
& \mathrm{dQ}_{1 \rightarrow 2^{\prime}}^{\mathrm{AC}}=\mathrm{dQ}_{\mathrm{mc}}^{\mathrm{AC}}+\mathrm{dQ}_{\text {sorbent }}^{\mathrm{AC}}+\mathrm{dQ}_{\text {adsorbat }}^{\mathrm{AC}}+\mathrm{dQ}_{\text {vapor }}^{\mathrm{AC}}
\end{aligned}
$$

The energy is introduced to the metallic components (copper tubes and aluminum fins) of the com-reactor causes a step temperature increase.

$$
\begin{aligned}
& \mathrm{dQ}_{\mathrm{mc}}^{\mathrm{SG}}=\left[\left(\mathrm{M}_{\mathrm{t}, \mathrm{cu}} \cdot \mathrm{C}_{\mathrm{P}, \mathrm{Cu}}+\mathrm{M}_{\mathrm{f}, \mathrm{Al}} \cdot \mathrm{C}_{\mathrm{P}, \mathrm{Al}}\right) \cdot \mathrm{dT}\right]_{1 \rightarrow 2}^{\mathrm{SG}} \\
& \mathrm{dQ} \mathrm{mc}_{\mathrm{mc}}^{\mathrm{AC}}=\left[\left(\mathrm{M}_{\mathrm{t}, \mathrm{cu}} \cdot \mathrm{C}_{\mathrm{P}, \mathrm{Cu}}+\mathrm{M}_{\mathrm{f}, \mathrm{Al}} \cdot \mathrm{C}_{\mathrm{P}, \mathrm{Al}}\right) \cdot \mathrm{dT}\right]_{1 \rightarrow 2}^{\mathrm{AC}}
\end{aligned}
$$

The thermal energy consumed in sensible heating of the solid adsorbent media causes a step temperature rise from $T_{1}$ to $T_{2}$ for SG-adsorbent bed and from $T_{1}$ to $T_{2}, A C$-adsorbent bed.

$$
\mathrm{dQ}_{\text {sorbent }}^{\mathrm{SG}}=\left[\mathrm{M}_{\mathrm{SG}} \cdot \mathrm{C}_{\mathrm{P}, \mathrm{S}} \cdot \mathrm{dT}\right]_{1 \rightarrow 2}^{\mathrm{SG}}
$$

$$
\mathrm{dQ}_{\text {sorbent }}^{\mathrm{AC}}=\left[\left[\mathrm{M}_{\mathrm{AC}} \cdot \mathrm{C}_{\mathrm{P}, \mathrm{s}} \cdot \mathrm{dT}\right]\right]_{1 \rightarrow 2^{\prime}}^{\mathrm{AC}}
$$

During the preheating process, there is no desorption taking place and therefore, the mass of the adsorbate phase $M_{a}$ remains constant. The differential amount of energy input to the adsorbate phase (methanol liquid) appears in the increase of the adsorbate internal energy and is given by:

$$
\begin{aligned}
& \mathrm{dQ}_{\mathrm{adsorbat}}^{\mathrm{SG}}=\left[\mathrm{M}_{\mathrm{a}} \cdot \mathrm{du}_{\mathrm{a}}\right]_{1 \rightarrow 2}=\left[\mathrm{X}_{\text {max }}^{\mathrm{SG}} \cdot \mathrm{M}_{\mathrm{SG}} \cdot \mathrm{C}_{\mathrm{V}, \mathrm{a}} \cdot \mathrm{dT}\right]_{1 \rightarrow 2}^{\mathrm{SG}} \\
& \mathrm{dQ}_{\text {adsorbat }}^{\mathrm{AC}}=\left[\mathrm{M}_{\mathrm{a}} \cdot \mathrm{du}_{\mathrm{a}}\right]_{1 \rightarrow 2}=\left[\mathrm{X}_{\max }^{\mathrm{AC}} \cdot \mathrm{M}_{\mathrm{AC}} \cdot \mathrm{C}_{\mathrm{V}, \mathrm{a}} \cdot \mathrm{dT}\right]_{1 \rightarrow 2^{\prime}}^{\mathrm{AC}}
\end{aligned}
$$

The differential amount of energy required by the refrigerant vapor phase is calculated as follows:

$$
\begin{aligned}
& \mathrm{dQ}_{\text {vapor }}^{\mathrm{SG}}=\left[\mathrm{M}_{\mathrm{v}} \cdot \mathrm{du}_{\mathrm{v}}\right]_{1 \rightarrow 2}=\left[\mathrm{M}_{\mathrm{v}} \cdot \mathrm{C}_{\mathrm{V}, \mathrm{v}} \cdot \mathrm{dT}\right]_{1 \rightarrow 2}^{\mathrm{SG}} \\
& \mathrm{dQ}_{\mathrm{vapor}}^{\mathrm{AC}}=\left[\mathrm{M}_{\mathrm{v}} \cdot \mathrm{du}_{\mathrm{v}}\right]_{1 \rightarrow 2}=\left[\mathrm{M}_{\mathrm{v}} \cdot \mathrm{C}_{\mathrm{V}, \mathrm{v}} \cdot \mathrm{dT}\right]_{1 \rightarrow 2^{\prime}}^{\mathrm{AC}}
\end{aligned}
$$

where $M_{v}$ is the mass of the vapor phase which remains constant during pre-heating process and is given by:

$M_{v}=\rho_{v}\left(P_{\text {evap }}, T_{1}\right) \cdot(\beta-\emptyset) \cdot V$

The variation of the adsorbate volume fraction $\phi$, along the highest concentration path can be determined from the following equation [20].

$$
\emptyset=X_{\max } \cdot \frac{\rho_{\mathrm{s}}}{\rho_{\mathrm{a}}(\mathrm{T})} \cdot(1-\beta)
$$




\subsection{Isobaric Heating and Desorption Process}

Both the SG the $A C$ adsorbents during isobaric heating undergoes the desorption phase at the same constant condenser pressure. The methanol concentration by the SG-particles decreases by increasing the desorption temperature from the maximum value $X_{\max }^{S G}\left(P_{\text {cond }}, T_{\text {cond }}\right)$ to the minimum value $X_{\min }^{S G}\left(P_{c o n d}, T_{b}\right)$ and the methanol concentration by the AC-particles decreases during this process from $X_{\max }^{A C}\left(P_{\text {cond }}, T_{\text {cond }}\right)$ to $X_{\min }^{A C}\left(P_{\text {cond }}, T_{b}\right)$.

The variation of the adsorbate concentration ratio along the isobaric heating process is defined by the following equation:

$$
\mathrm{X}=\mathrm{X}_{0} \exp \left\{-\mathrm{D} \cdot\left[\mathrm{T}_{\text {des }} \cdot \ln \left(\frac{\mathrm{P}_{\text {sat }}\left(\mathrm{T}_{\text {des }}\right)}{\mathrm{P}_{\text {cond }}}\right)\right]^{\mathrm{n}}\right\}
$$

The amount of the added energy $\mathrm{Q}_{\text {des }}^{\text {add }}$ which is required during the isobaric heating process causes sensible heating of the com-adsorption reactor constituents, activates the desorption of the refrigerant from the adsorbent media (SG, AC) and generates the gas phase. This added energy can be expressed as follows:

$\mathrm{dQ}_{\mathrm{des}}^{\text {add }}=\mathrm{dQ}_{2 \rightarrow 3}^{\mathrm{SG}}+\mathrm{dQ}_{2 \rightarrow 3}^{\mathrm{AC}}$

$\mathrm{dQ}_{2 \rightarrow 3}^{\mathrm{SG}}=\left[\mathrm{dQ}_{\mathrm{mc}}^{\mathrm{SG}}+\mathrm{dQ}_{\text {sorbent }}^{\mathrm{SG}}+\mathrm{dQ}_{\text {adsorbat }}^{\mathrm{SG}}+\mathrm{dQ}_{\text {vapor }}^{\mathrm{SG}}\right]_{2 \rightarrow 3}$

$\mathrm{dQ}_{2^{\prime} \rightarrow 3^{\prime}}^{\mathrm{AC}}=\left[\mathrm{dQ}_{\mathrm{mc}}^{\mathrm{AC}}+\mathrm{dQ}_{\text {sorbent }}^{\mathrm{AC}}+\mathrm{dQ}_{\text {adsorbat }}^{\mathrm{AC}}+\mathrm{dQ}_{\text {vapor }}^{\mathrm{AC}}\right]_{2^{\prime} \rightarrow 3}$

The energy is introduced to the metallic components (copper tubes and aluminum fins) of the com-adsorption reactor causes a step temperature rise

$\mathrm{dQ}_{\mathrm{mc}}^{\mathrm{SG}}=\left[\left(\mathrm{M}_{\mathrm{t}, \mathrm{cu}} \cdot \mathrm{C}_{\mathrm{P}, \mathrm{Cu}}+\mathrm{M}_{\mathrm{f}, \mathrm{Al}} \cdot \mathrm{C}_{\mathrm{P}, \mathrm{Al}}\right) \cdot \mathrm{dT}\right]_{2 \rightarrow 3}^{\mathrm{SG}}$

$\mathrm{dQ}_{\mathrm{mc}}^{\mathrm{AC}}=\left[\left(\mathrm{M}_{\mathrm{t}, \mathrm{cu}} \cdot \mathrm{C}_{\mathrm{P}, \mathrm{Cu}}+\mathrm{M}_{\mathrm{f}, \mathrm{Al}} \cdot \mathrm{C}_{\mathrm{P}, \mathrm{Al}}\right) \cdot \mathrm{dT}\right]_{2^{\prime} \rightarrow 3}^{\mathrm{AC}}$

The thermal energy consumed in sensible heating of the solid adsorbent media causes a step temperature rise from $T_{2}$ to $T_{3}$ for SG-bed and from $T_{2}$, to $T_{3}$, for AC-bed.

$\mathrm{dQ}_{\text {sorbent }}^{\mathrm{SG}}=\left[\mathrm{M}_{\mathrm{SG}} \cdot \mathrm{C}_{\mathrm{P}, \mathrm{s}} \cdot \mathrm{dT}\right]_{2 \rightarrow 3}$
$\mathrm{dQ}_{\text {sorbent }}^{\mathrm{AC}}=\left[\mathrm{M}_{\mathrm{AC}} \cdot \mathrm{C}_{\mathrm{P}, \mathrm{s}} \cdot \mathrm{dT}\right]_{2^{\prime} \rightarrow 3}$.

The differential amount of energy input to the adsorbate phase appears in the increase of the adsorbate (liquid methanol) and refrigerant vapor internal energy.

By applying in this case the conservation of energy principle on the adsorbate and refrigerant vapor phase [25], we get:

$$
\begin{aligned}
& \mathrm{dQ}_{\mathrm{adsorbat}}^{\mathrm{SG}}=\left[\mathrm{dU}_{\mathrm{a}}^{\mathrm{SG}}\right]_{2 \rightarrow 3}=\left[\mathrm{d}\left(\mathrm{M}_{\text {adsorbent }} \cdot \mathrm{u}_{\mathrm{a}}\right)\right]_{2 \rightarrow 3} \\
& =\left[\mathrm{M}_{\mathrm{SG}} \cdot \mathrm{C}_{\mathrm{P}, \text { adsorbent }} \cdot \mathrm{d}(\mathrm{X} \cdot \mathrm{T})\right]_{2 \rightarrow 3}^{\mathrm{SG}} \\
& \mathrm{dQ}_{\mathrm{adsorbat}}^{\mathrm{AC}}=\left[\mathrm{dU}_{\mathrm{a}}^{\mathrm{AC}}\right]_{2^{\prime} \rightarrow 3^{\prime}}=\left[\mathrm{d}\left(\mathrm{M}_{\text {adsorbent }} \cdot \mathrm{u}_{\mathrm{a}}\right)\right]_{2^{\prime} \rightarrow 3^{\prime}} \\
& =\left[\mathrm{M}_{\mathrm{AC}} \cdot \mathrm{C}_{\mathrm{P}, \text { adsorbent }} \cdot \mathrm{d}(\mathrm{X} \cdot \mathrm{T})\right]_{2^{\prime} \rightarrow 3}^{\mathrm{AC}}
\end{aligned}
$$

where $\mathrm{dU}_{\mathrm{a}}$ is the step change in the total internal energy of the adsorbate refrigerant phase. Regarding the mass of the refrigerant vapor phase is varying during the desorption process.

The differential amount of energy input to the vapor phase appears in the increase of the refrigerant vapor internal energy.

$$
\begin{array}{r}
\mathrm{d}_{\text {vapor }}^{\mathrm{SG}}=\left[\mathrm{dU}_{\mathrm{v}}^{\mathrm{SG}}+\mathrm{dM}_{\text {des }} \mathrm{h}_{\mathrm{v}}\right]_{2 \rightarrow 3}=\left[\mathrm{d}\left(\mathrm{M}_{\mathrm{v}} \cdot \mathrm{u}_{\mathrm{v}}\right)+\mathrm{dM}_{\text {des }} \mathrm{h}_{\mathrm{v}}\right]_{2 \rightarrow 3}^{\mathrm{SG}} \\
\mathrm{dQ}_{\text {vapor }}^{\mathrm{AC}}=\left[\mathrm{dU}_{\mathrm{v}}^{A \mathrm{C}}+\mathrm{dM}_{\mathrm{des}} \mathrm{h}_{\mathrm{v}}\right]_{2^{\prime} \rightarrow 3^{\prime}}=\left[\mathrm{d}\left(\mathrm{M}_{\mathrm{v}} \cdot \mathrm{u}_{\mathrm{v}}\right)+\mathrm{dM}_{\text {des }} \mathrm{h}_{\mathrm{v}}\right]_{2^{\prime} \rightarrow 3^{\prime}}^{\mathrm{AC}}
\end{array}
$$

The differential amount of energy which is transported from the adsorption reactor to the condenser is given by:

$\mathrm{d} \mathrm{Q}_{\text {cond }}=\delta \mathrm{M}_{\text {cond }} \cdot \mathrm{h}_{\mathrm{v}}\left(\mathrm{P}_{\text {cond }}, \mathrm{T}\right)$

where $\delta \mathrm{M}_{\text {cond }}$ is the differential mass that leaves the com-adsorption reactor and flows towards the condenser and equals the total refrigerant mass content inside the SG-particles and AC-particles. This infinitesimal amount of mass can be written as follows:

$\delta \mathrm{M}_{\text {cond }}=\mathrm{dM}_{\mathrm{des}}=\left[\mathrm{dM}_{\mathrm{a}}+\mathrm{dM}_{\mathrm{v}}\right]_{2 \rightarrow 3}^{\mathrm{SG}}+\left[\mathrm{dM}_{\mathrm{a}}+\mathrm{dM}_{\mathrm{v}}\right]_{2^{\prime} \rightarrow 3}^{\mathrm{AC}}$ 


\subsection{Isostatic Cooling and Depressurization Process}

Like the pre-heating process, the methanol concentration remains constant. In this process, the com-adsorption reactor is precooled at two constant isostere lines $X_{\min }=f\left(T_{\max }, P_{\text {cond }}\right)$ for $A C$-bed and SGbed.

The rejected energy $Q_{\text {cooling }}^{\text {reject }}$ during the precooling process of com-adsorption reactor causes sensible cooling of the adsorption reactor constituents. This differential amount of energy which lost from the adsorption reactor to the ambient surroundings is given by:

$$
\begin{aligned}
& \mathrm{dQ}_{\text {cooling }}^{\text {reject }}=\mathrm{dQ}_{3 \rightarrow 4}^{\mathrm{SG}}+\mathrm{dQ}_{3^{\prime} \rightarrow 4^{\prime}}^{\mathrm{AC}} \\
& \mathrm{dQ}_{3^{\mathrm{SG}} \rightarrow 4}^{\mathrm{SG}}=\mathrm{dQ}_{\mathrm{mc}}^{\mathrm{SG}}+\mathrm{dQ}_{\text {sorbent }}^{\mathrm{SG}}+\mathrm{dQ}_{\text {adsorbat }}^{\mathrm{SG}}+\mathrm{dQ}_{\text {vapor }}^{\mathrm{SG}} \\
& \mathrm{dQ}_{3^{\circ} \rightarrow 4^{\prime}}^{\mathrm{AC}}=\mathrm{dQ}_{\mathrm{mc}}^{\mathrm{AC}}+\mathrm{dQ}_{\text {sorbent }}^{\mathrm{AC}}+\mathrm{dQ}_{\text {adsorbat }}^{\mathrm{AC}}+\mathrm{dQ}_{\text {vapor }}^{\mathrm{AC}}
\end{aligned}
$$

By the same methodology which has been followed in preheating process, the energy is lost from the metallic components (copper tube and aluminum fins) of the generator is calculated from following equations:

$$
\begin{aligned}
& \mathrm{dQ}_{\mathrm{mc}}^{\mathrm{SG}}=\left[\left(\mathrm{M}_{\mathrm{t}, \mathrm{cu}} \cdot \mathrm{C}_{\mathrm{P}, \mathrm{Cu}}+\mathrm{M}_{\mathrm{f}, \mathrm{Al}} \cdot \mathrm{C}_{\mathrm{P}, \mathrm{Al}}\right) \cdot \mathrm{dT}\right]_{3 \rightarrow 4}^{\mathrm{SG}} \\
& \mathrm{dQ} \mathrm{mc}=\left[\left(\mathrm{M}_{\mathrm{t}, \mathrm{cu}} \cdot \mathrm{C}_{\mathrm{P}, \mathrm{Cu}}+\mathrm{M}_{\mathrm{f}, \mathrm{Al}} \cdot \mathrm{C}_{\mathrm{P}, \mathrm{Al}}\right) \cdot \mathrm{dT}\right]_{3^{\prime} \rightarrow 4^{\mathrm{A}}}^{\mathrm{AC}}
\end{aligned}
$$

The thermal energy which is lost in sensible form of the solid adsorbent media causes a drop temperature from $T_{3}$ to $T_{4}$ for SG- bed and from $T_{3}$ to $T_{4}$, AC-bed.

$$
\begin{aligned}
& \mathrm{dQ}_{\text {sorbent }}^{\mathrm{SG}}=\left[\mathrm{M}_{\mathrm{SG}} \cdot \mathrm{C}_{\mathrm{P}, \mathrm{s}} \cdot \mathrm{dT}\right]_{3 \rightarrow 4} \\
& \mathrm{dQ}_{\text {sorbent }}^{\mathrm{AC}}=\left[\mathrm{M}_{\mathrm{AC}} \cdot \mathrm{C}_{\mathrm{P}, \mathrm{s}^{\prime}} \cdot \mathrm{dT}\right]_{3^{\prime} \rightarrow 4^{\prime}}
\end{aligned}
$$

The differential amount of energy output from the adsorbate refrigerant appears in the decrease of the adsorbate internal energy. During the pre-cooling process, there is no desorption/adsorption taking place and therefore, the mass of the adsorbate phase $M_{a}$ remains constant and is given by:

$$
\begin{aligned}
& \mathrm{dO}_{\text {ndmonhnt }}^{\mathrm{SG}}=\left\lceil\mathrm{M}_{\text {adenrhant }} \cdot \mathrm{du}_{\mathrm{n}}\right\rceil_{2 \rightarrow 4} \\
& =\left[\mathrm{X}_{\mathrm{min}}^{\mathrm{SG}} \cdot \mathrm{M}_{\mathrm{SG}} \cdot \mathrm{C}_{\mathrm{V} \text {,adsorbent }} \cdot \mathrm{dT}\right]_{3 \rightarrow 4}^{\mathrm{SG}}
\end{aligned}
$$

$$
\begin{aligned}
& \mathrm{dQ}_{\mathrm{adsn} \text { hat }}^{\mathrm{AC}}=\left[\mathrm{M}_{\text {adsorhent }} \cdot \mathrm{du}_{\mathrm{a}}\right]_{3^{\prime} \rightarrow 4^{`}} \\
& =\left[\mathrm{X}_{\mathrm{min}}^{\mathrm{AC}} \cdot \mathrm{M}_{\mathrm{AC}} \cdot \mathrm{C}_{\mathrm{V}, \text { adsorbent }} \cdot \mathrm{dT}\right]_{3^{\prime} \rightarrow 4^{\prime}}^{\mathrm{AC}}
\end{aligned}
$$

The differential amount of energy losses from the refrigerant vapor phase is calculated as follows:

$$
\begin{aligned}
& \mathrm{dQ}_{\text {vapor }}^{\mathrm{SG}}=\left[\mathrm{M}_{\mathrm{v}} \cdot \mathrm{du}_{\mathrm{v}}\right]_{3 \rightarrow 4}=\left[\mathrm{M}_{\mathrm{v}} \cdot \mathrm{C}_{\mathrm{V}, \mathrm{v}} \cdot \mathrm{dT}\right]_{3 \rightarrow 4}^{\mathrm{SG}} \\
& \mathrm{dQ}_{\text {vapor }}^{\mathrm{AC}}=\left[\mathrm{M}_{\mathrm{v}} \cdot \mathrm{du}_{\mathrm{v}}\right]_{3^{\prime} \rightarrow 4^{\prime}}=\left[\mathrm{M}_{\mathrm{v}} \cdot \mathrm{C}_{\mathrm{V}, \mathrm{v}} \cdot \mathrm{dT}\right]_{3^{\prime} \rightarrow 4^{\prime}}^{\mathrm{AC}}
\end{aligned}
$$

Where $M_{v}$ is the mass of the vapor phase which remains constant during precooling process and is given by:

$M_{v}=\rho_{v}\left(P_{\text {cond }}, T_{\max }\right) \cdot\left(\beta-\emptyset_{3 \rightarrow 4}\right) \cdot V$

The variation of the adsorbate volume fraction, along the lowest concentration path can be determined from the following equation [20].

$\emptyset_{3 \rightarrow 4}=X_{\min } \cdot \frac{\rho_{\mathrm{s}}}{\rho_{\mathrm{a}}\left(\mathrm{T}_{3 \rightarrow 4}\right)} \cdot(1-\beta)$

\subsection{Isobaric Cooling and Adsorption Process}

The com-adsorption reactor during isobaric cooling undergoes the adsorption phase at the same constant evaporator pressure and is cooled at the ambient temperature. By decreasing the temperature the methanol concentration by the SG-particles increases from the minimum value $\mathrm{X}_{\min }^{\mathrm{SG}}\left(\mathrm{P}_{\text {cond }}, \mathrm{T}_{\text {des, max }}\right)$ to the maximum value $\mathrm{X}_{\max }^{\mathrm{SG}}\left(\mathrm{P}_{\text {evap }}, \mathrm{T}_{\mathrm{amb}}\right)$ and the methanol concentration by the $\mathrm{AC}$-particles decreases during this process from $\mathrm{X}_{\min }^{\mathrm{AC}}\left(\mathrm{P}_{\text {cond }}, \mathrm{T}_{\text {des, } \max }\right)$ to $\mathrm{X}_{\max }^{\mathrm{AC}}\left(\mathrm{P}_{\text {evap }}, \mathrm{T}_{\mathrm{amb}}\right)$.

The variation of the adsorbate concentration ratio along the isobaric cooling process is defined by the following equation:

$\mathrm{X}=\mathrm{X}_{0} \exp \left\{-\mathrm{D} \cdot\left[\mathrm{T}_{\mathrm{ads} \rightarrow \mathrm{amb}} \cdot \ln \left(\frac{\mathrm{P}_{\mathrm{sat}}\left(\mathrm{T}_{\mathrm{ads} \rightarrow \mathrm{amb}}\right)}{\mathrm{P}_{\text {evap }}}\right)\right]^{\mathrm{n}}\right\}$

The amount of the rejected energy $Q_{\text {ads }}^{\text {rejet }}$ which is lost during the isobaric cooling process causes sensible cooling of the com-adsorption reactor constituents and activates the adsorption of the refrigerant from the adsorbent media (SG, AC). This rejected energy can be expressed as follows: 


$$
\begin{aligned}
& \mathrm{dQ}_{\text {ads }}^{\text {reject }}=\mathrm{dQ}_{4 \rightarrow 1}^{\mathrm{SG}}+\mathrm{dQ}_{4^{\prime} \rightarrow 1}^{\mathrm{AC}} \\
& \mathrm{dQ}_{4 \rightarrow 1}^{\mathrm{SG}}=\left[\mathrm{dQ}_{\mathrm{mc}}^{\mathrm{SG}}+\mathrm{dQ}_{\text {sorbent }}^{\mathrm{SG}}+\mathrm{dQ}_{\text {adsorbat }}^{\mathrm{SG}}+\mathrm{dQ}_{\text {vapor }}^{\mathrm{SG}}\right]_{4 \rightarrow 1} \\
& \mathrm{dQ}_{4^{\prime} \rightarrow 1}^{\mathrm{AC}}=\left[\mathrm{dQ}_{\mathrm{mc}}^{\mathrm{AC}}+\mathrm{dQ}_{\text {sorbent }}^{\mathrm{AC}}+\mathrm{dQ}_{\text {adsorbat }}^{\mathrm{AC}}+\mathrm{dQ}_{\text {vapor }}^{\mathrm{AC}}\right]_{4^{\prime} \rightarrow 1}
\end{aligned}
$$

The energy which is lost from the metallic components (copper tubes and aluminum fins) of the generator is calculated from following equations:

$$
\begin{gathered}
\mathrm{dQ}_{\mathrm{mc}}^{\mathrm{SG}}=\left[\left(\mathrm{M}_{\mathrm{t}, \mathrm{cu}} \cdot \mathrm{C}_{\mathrm{P}, \mathrm{Cu}}+\mathrm{M}_{\mathrm{f}, \mathrm{Al}} \cdot \mathrm{C}_{\mathrm{P}, \mathrm{Al}}\right) \cdot \mathrm{dT}\right]_{4 \rightarrow 1}^{\mathrm{SG}} \\
\mathrm{d} \mathrm{Q}_{\mathrm{mc}}^{\mathrm{AC}}=\left[\left(\mathrm{M}_{\mathrm{t}, \mathrm{cu}} \cdot \mathrm{C}_{\mathrm{P}, \mathrm{Cu}}+\mathrm{M}_{\mathrm{f}, \mathrm{Al}} \cdot \mathrm{C}_{\mathrm{P}, \mathrm{Al}}\right) \cdot \mathrm{dT}\right]_{4 \rightarrow 1}^{\mathrm{AC}}
\end{gathered}
$$

The thermal energy which is lost in sensible form of the solid adsorbent media causes a drop temperature from $T_{4}$ to $T_{1}$ for $S G$-bed and from $T_{4}$, to $T_{1} A C$-bed.

$$
\begin{aligned}
& \mathrm{dQ}_{\text {sorbent }}^{\mathrm{SG}}=\left[\mathrm{M}_{\mathrm{SG}} \cdot \mathrm{C}_{\mathrm{P}, \mathrm{s}} \cdot \mathrm{dT}\right]_{4 \rightarrow 1} \\
& \mathrm{dQ}_{\text {sorbent }}^{\mathrm{AC}}=\left[\mathrm{M}_{\mathrm{AC}} \cdot \mathrm{C}_{\mathrm{P}, \mathrm{s}} \cdot \mathrm{dT}\right]_{4^{\prime} \rightarrow 1}
\end{aligned}
$$

The differential amount of energy output from the adsorbate phase appears in the decrease of the adsorbate and refrigerant vapor internal energy. By applying in this case the conservation of energy principle on the adsorbate and refrigerant vapor phase, we get [25]:

$$
\begin{aligned}
& \mathrm{dQ}_{\text {adsorbat }}^{\mathrm{SG}}=\left[\mathrm{dU}_{\mathrm{a}}^{\mathrm{SG}}\right]_{4 \rightarrow 1}=\left[\mathrm{d}\left(\mathrm{M}_{\text {adsorbent }} \cdot \mathrm{u}_{\mathrm{a}}\right)\right]_{4 \rightarrow 1} \\
& =\left[\mathrm{M}_{\mathrm{SG}} \cdot \mathrm{C}_{\mathrm{P}, \text { adsorbent }} \cdot \mathrm{d}(\mathrm{X} . \mathrm{T})\right]_{4 \rightarrow 1}^{\mathrm{SG}} \\
& \mathrm{dQ}_{\mathrm{adsorbat}}^{\mathrm{AC}}=\left[\mathrm{dU}_{\mathrm{a}}^{\mathrm{AC}}\right]_{4^{\prime} \rightarrow 1}=\left[\mathrm{d}\left(\mathrm{M}_{\text {adsorbent }} \cdot \mathrm{u}_{\mathrm{a}}\right)\right]_{4^{\prime} \rightarrow 1} \\
& =\left[\mathrm{M}_{\mathrm{AC}} \cdot \mathrm{C}_{\mathrm{P}, \text { adsorbent }} \cdot \mathrm{d}(\mathrm{X} \cdot \mathrm{T})\right]_{4^{\prime} \rightarrow 1}^{\mathrm{AC}}
\end{aligned}
$$

Regarding the mass of the refrigerant vapor phase is varying during adsorption process. The differential amount of energy output from the vapor phase appears in the decrease of the refrigerant vapor internal energy.

$$
\begin{aligned}
& d Q_{\text {vapor }}^{S G}=\left[d_{v}^{S G}+d^{S G} M_{a d s} h_{v}\right]_{4 \rightarrow 1} \\
& =\left[d\left(M_{v} \cdot u_{v}\right)+d_{\text {ads }} h_{v}\right]_{4 \rightarrow 1}^{S G}
\end{aligned}
$$

$$
\mathrm{dQ}_{\mathrm{vapor}}^{\mathrm{AC}}=\left[\mathrm{dU}_{\mathrm{v}}^{\mathrm{AC}}+\mathrm{dM}_{\mathrm{ads}} \mathrm{h}_{\mathrm{v}}\right]_{4^{\prime} \rightarrow 1}=\left[\mathrm{d}\left(\mathrm{M}_{\mathrm{v}} \cdot \mathrm{u}_{\mathrm{v}}\right)+\mathrm{dM}_{\mathrm{ads}} \mathrm{h}_{\mathrm{v}}\right]_{4^{\prime} \rightarrow 1}^{\mathrm{AC}}
$$

The differential amount of energy which is transported from the evaporator to the com-adsorption reactor is given by:

$$
\mathrm{dQ}_{\text {evap }}=\delta \mathrm{M}_{\text {evap }} \cdot \mathrm{h}_{\mathrm{v}}\left(\mathrm{P}_{\text {evap }}, \mathrm{T}_{\text {evap }}\right)
$$

where $\delta M_{\text {evap }}$ is the differential mass that leaves the evaporator and enters the com-adsorption reactor and equals the total refrigerant mass content inside both the SG adsorbent and AC adsorbent. This infinitesimal amount of mass can be written as follows:

$$
\delta M_{\text {evap }}=\mathrm{dM}_{\mathrm{ads}}=\left[\mathrm{dM}_{\mathrm{a}}+\mathrm{dM}_{\mathrm{v}}\right]_{4 \rightarrow 1}^{\mathrm{SG}}+\left[\mathrm{dM}_{\mathrm{a}}+\mathrm{dM}_{\mathrm{v}}\right]_{4^{\circ} \rightarrow 1}^{\mathrm{AC}}
$$

\subsection{The Condenser}

As soon as the refrigerant vapor desorbs from the com-adsorption reactor, it enters the condenser. In the condenser, the refrigerant gas is being de super heated first by removing sensible energy from the superheated vapor across a driving temperature difference of $T_{b}$ $\mathrm{T}_{\text {cond. }}$ By rejecting the latent energy of condensation $\Delta \mathrm{H}_{\text {cond }}$ to the ambient heat sink the refrigerant vapor starts to condense. The condensation energy of $m_{\text {cond }}$ is given by:

$$
\mathrm{Q}_{\text {cond }}=\mathrm{m}_{\text {cond }} \cdot\left[\mathrm{h}_{\mathrm{g}}\left(\mathrm{P}_{\text {cond }}, \mathrm{T}_{\mathrm{b}}\right)-\mathrm{h}_{\text {sat }}\left(\mathrm{P}_{\text {cond }}\right)+\Delta \mathrm{H}_{\text {cond }}\right]
$$

$h_{\text {sat }}\left(P_{\text {cond }}\right)$ : the refrigerant vapor saturation specific enthalpy at the condensation presssure.

\subsection{The Evaporator}

In the evaporator, the ice production takes place by the evaporation of the saturated liquid refrigerant. The differential evaporation effect $\delta \mathrm{Q}_{\text {evap }}$ is calculated from following equation [20]:

$$
\delta \mathrm{Q}_{\text {evap }}=\delta \mathrm{M}_{\text {evap }} \cdot\left[(1-\mathrm{z}) \cdot \mathrm{L}_{\mathrm{e}}+\left(\mathrm{h}_{\text {evap }}(\mathrm{T})-\mathrm{h}_{\text {sat }}\left(\mathrm{P}_{\text {evap }}\right)\right)\right]
$$

The cooling effect is associated with a differential amount of refrigerant liquid $\delta \mathrm{M}_{\text {evap }}$, which is coming from the evaporator and is being adsorbed in the comadsorption reactor.

$\delta \mathrm{m}_{\text {evap }}=\delta \mathrm{m}_{\text {ads }}$ 
The cold adsorption system is used for freezing applications; the total amount of the ice produced from the com-AIP system per cycle is given by;

$$
\delta \mathrm{m}_{\mathrm{ice}}=\frac{\delta \mathrm{Q}_{\mathrm{e}}}{\left[\mathrm{C}_{\mathrm{ch}, \mathrm{in}} \cdot\left(\mathrm{T}_{\mathrm{ch}, \text { in }}-273\right)+\mathrm{L}_{\mathrm{f}}+\mathrm{C}_{\mathrm{ice}} \cdot\left(273-\mathrm{T}_{\mathrm{e}}+\Delta \varphi_{\mathrm{e}}\right)\right]}
$$

$\delta \mathrm{Q}_{\mathrm{evap}} \cong \delta \mathrm{Q}_{\mathrm{e}}$

The coefficient of performance COP is defined as the ratio of the refrigeration capacity $Q_{e}$ and the input energy $Q_{i n}$ to the com-adsorption reactor during the isosteric and isobaric heating processes.

$\mathrm{COP}=\frac{\mathrm{Q}_{\mathrm{e}}}{\mathrm{Q}_{\mathrm{in}}}$

In this equation, the required input energy to drive the com-AIM system is given by;

$$
\begin{aligned}
& Q_{\text {in }}=\int d Q_{\text {heating }}^{\text {add }}+d_{\text {des }}^{\text {add }} \\
& Q_{\text {in }}=\int d Q_{1 \rightarrow 2}^{S G}+\int d Q_{1 \rightarrow 2^{\prime}}^{A C}+\int d Q_{2 \rightarrow 3}^{S G}+\int d Q_{2^{\prime} \rightarrow 3^{\prime}}^{A C}
\end{aligned}
$$

\section{CALCULATION PROCEDURE}

The analysis of the combined Adsorption Ice Maker AIP system with com-heat exchanger has been investigated using a simulation program written in MATLAB. This program is designed to analyze the thermodynamic cycle parameters of this technique. The above mentioned set of coupled equations is solved by finite difference approximation with a temperature step of one grad Celsius and with a time step of one second. The investigation focused on the effect of the adsorption reactor temperature $\mathrm{T}_{\mathrm{b}}$, the desorbed refrigerant mass from com- adsorption reactor $m_{\text {des }}$, the cycle time $t_{\text {cycle }}$ and the amount of produced ice $m_{\text {ice }}$.

For evaluation of the com-AIP system according to thermodynamic analysis, the comparison with two systems: SG-bed AIP system and AC-bed AIP system is investigated.

The case investigated in the present study is an ice maker at an evaporation temperature of $-3{ }^{\circ} \mathrm{C}$. The new strategy operates with silica $\mathrm{gel} / \mathrm{methanol}$ as the first working pair in the SG-bed and operates with activated carbon/methanol as the second working pair in the ACbed of com-adsorption reactor. The characteristics of activated carbon and silica gel, packed in this adsorption reactor, are shown in Table 3 . The configuration of these sorption elements is identical and taken as same size. In the proposed design the effect of metallic casing of the com- adsorption bed is taken into account.

Table 3: The Characteristics of Maxsorb Activated Carbon and Silica Gel used in this Study. (Data Reported by Kanasi Coke and Chemical, Japan)

\begin{tabular}{|c|c|c|}
\hline Parameter & Activated Carbon & Silica Gel \\
\hline \hline Absolute density $\rho_{s}$ & $400-600\left[\mathrm{~kg} / \mathrm{m}^{3}\right]$ & $700-750\left[\mathrm{~kg} / \mathrm{m}^{3}\right]$ \\
\hline BET surface area & $2250\left[\mathrm{~m}^{2} / \mathrm{gr}\right]$ & $800\left[\mathrm{~m}^{2} / \mathrm{gr}\right]$ \\
\hline Specific heat capacity $C_{P}$ & $0.93[\mathrm{~kJ} / \mathrm{kg} \cdot \mathrm{K}]$ & $0.92[\mathrm{~kJ} / \mathrm{kg} \cdot \mathrm{K}]$ \\
\hline $\mathrm{X}_{0}$ & $1.24 \mathrm{~kg} / \mathrm{kg}_{\mathrm{ac}}$ & $0.35 \mathrm{~kg} \mathrm{~m}_{\mathrm{m}} / \mathrm{kg}_{\mathrm{ac}}$ \\
\hline $\mathrm{N}$ & 2,0 & 1,7 \\
\hline $\mathrm{D}$ & $4.022 \times 10^{-6}$ & \\
\hline $\mathrm{E}_{\mathrm{a}}$ & $306.766[\mathrm{~kJ} / \mathrm{kg}]$ & $1310.76[\mathrm{~kJ} / \mathrm{kg}]$ \\
\hline
\end{tabular}

The base parameters used in this case study are summarized in Table 4. The liquid and vapor thermodynamic properties of methanol have been calculated from the methanol equations [26]. The simulation uses embedded Ref prop thermo physical properties of methanol.

Table 4: The Base Parameters Used in this Case Study

\begin{tabular}{|c|c|c|c|}
\hline Parameter & Value & Parameter & Value \\
\hline \hline $\mathrm{T}_{\text {evap }}$ & $-3{ }^{\circ} \mathrm{C}$ & $\mathrm{T}_{\text {amb }}$ & $27^{\circ} \mathrm{C}$ \\
\hline $\mathrm{T}_{\text {cond }}$ & $32^{\circ} \mathrm{C}$ & $\mathrm{T}_{\max }$ & $100^{\circ} \mathrm{C}$ \\
\hline $\mathrm{P}_{\text {evap }}$ & $3.313[\mathrm{kpa}]$ & $\mathrm{P}_{\text {cond }}$ & $24[\mathrm{kpa}]$ \\
\hline
\end{tabular}

\section{RESULTS AND DISCUSSIONS OF THE CASE STUDY}

Based on the analysis for thermodynamic processes of the com-AIP system in Section 5 and the case study described in section 6 , it is found that the total input energy of the whole system equals $5766 \mathrm{~kJ}$, calculated as follows $Q_{\text {add }}=Q_{\text {heating }}^{S G}+Q_{\text {heating }}^{A C}+Q_{\text {des }}^{S G}$ $+Q_{\text {des }}^{A C}+Q_{\text {evap }}$ whereas, the total output energy of the system equals $5866 \mathrm{~kJ}$, calculated as follows $Q_{\text {rej }}=Q_{\text {cooling }}^{S G}+Q_{\text {cooling }}^{A C}+Q_{a d s}^{S G}+Q_{a d s}^{A C}+Q_{\text {cond }}$ therefore, the relative error in the calculations is nearly $1.75 \%$, calculated as follows $100 \times\left(Q_{a d d}-Q_{\text {rej }}\right) / Q_{\text {add }}$ this is an acceptable numerical error and validates the calculation accuracy. Based on the simulation results it 
is found that the com-AIP system attains a refrigeration COP of $73 \%$ with a refrigeration energy produced $Q_{e}$ inside the evaporator estimated to $2168 \mathrm{~kJ}$ per cycle. This refrigeration effect corresponds to ice production of $5.34 \mathrm{~kg}$ per cycle at a temperature of $-3{ }^{\circ} \mathrm{C}$ from water at a source temperature of $15^{\circ} \mathrm{C}$.

Therefore, every $1 \mathrm{~kg}$ of silica gel-particles inside this com-adsorption reactor produces ice mass of $0.4 \mathrm{~kg}$ per cycle and every $1 \mathrm{~kg}$ of activated carbonparticles inside the com-adsorption reactor produces ice mass of $1.13 \mathrm{~kg}$ per cycle under the hot water inlet temperature of $100^{\circ} \mathrm{C}$.

\subsection{Pressure Profile}

The adsorbate inlet condition during the adsorption process is performed at pressure of $3.31 \mathrm{kPa}$ corresponding to evaporation temperature of $-3{ }^{\circ} \mathrm{C}$. The refrigerant (adsorbate) outlet condition during desorption process is done at pressure of $24 \mathrm{kPa}$ corresponding to condensation temperature of $32^{\circ} \mathrm{C}$.

Plotting a variation of the pressure inside the comadsorption reactor, which is filled with two different adsorbents silica gel and activated carbon, is demonstrated along the cycle time Figure $\mathbf{5}$.

Based on the simulation results, it is found that the desorption and pre-cooling processes of the SG-bed begin before the same processes inside the AC-bed. Because of the properties of silica gel such as the specific heat capacity and the desorption heat, the duration of desorption process inside the SG-bed is $150 \mathrm{sec}$, whereas the desorption process inside the AC-bed is $287 \mathrm{sec}$. Consequently, both of the adsorbents work under the same pressures but with the different time.
The pressure level for isostericpre-heating and precooling is calculated by variation of the temperature in the heat exchanger of the com-adsorption reactor Eq. 4.

The Figure 6 shows the simulated pressure profile of the com-adsorption reactor for all of the cycle processes, the result corresponds to the ideal cycle displayed in Figure 2.

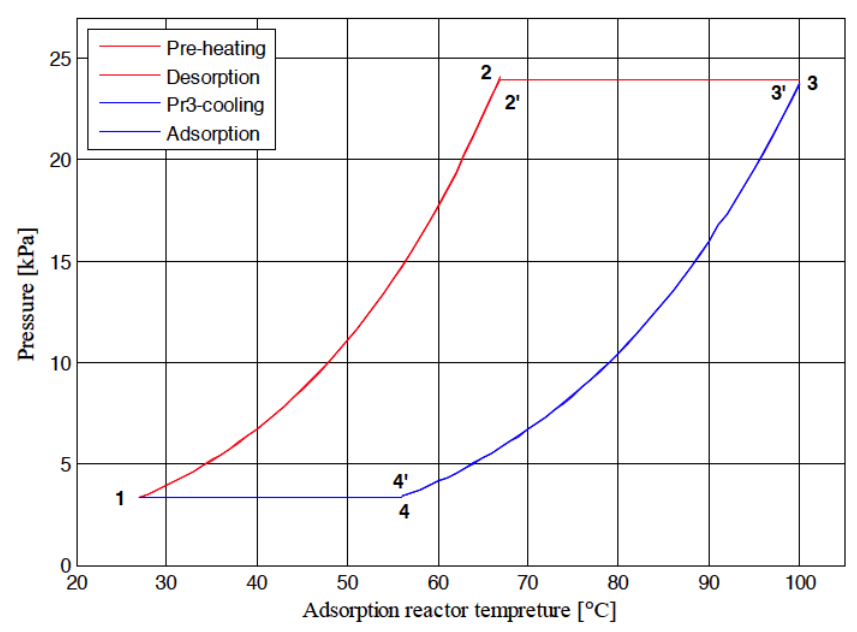

Figure 6: Variation of the com-reactor pressure versus the temperature along the cycle processes.

Although the com- AIP system use two adsorbents in the com-adsorption reactor, we can notice that the variation of the pressure inside both the $\mathrm{AC}$-bed and SG-bed related to the temperature remains identical. The adsorption reactor pressure rises from the evaporator pressure at $3.31 \mathrm{kpa}$ to the highest cycle pressure at the condenser of $24 \mathrm{kpa}$ during the isosteric pre-heating process. It can be also seen that the $A C$ and $S G$ adsorbents start the generation

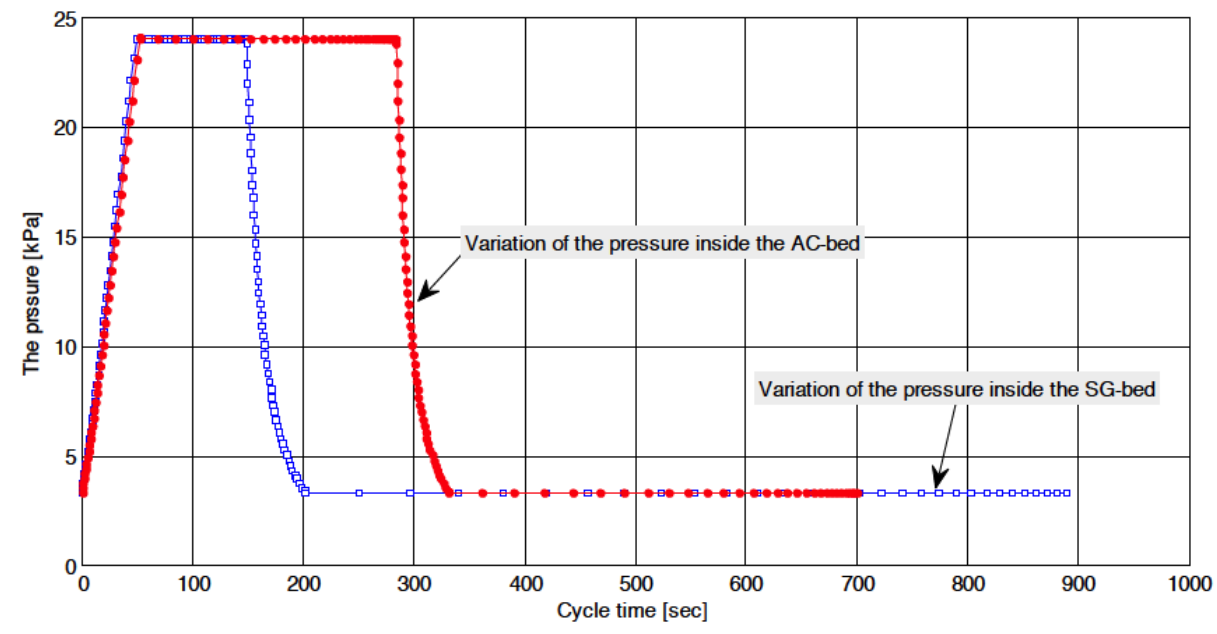

Figure 5: Variation of the com- adsorption reactor pressure along the cycle time. 


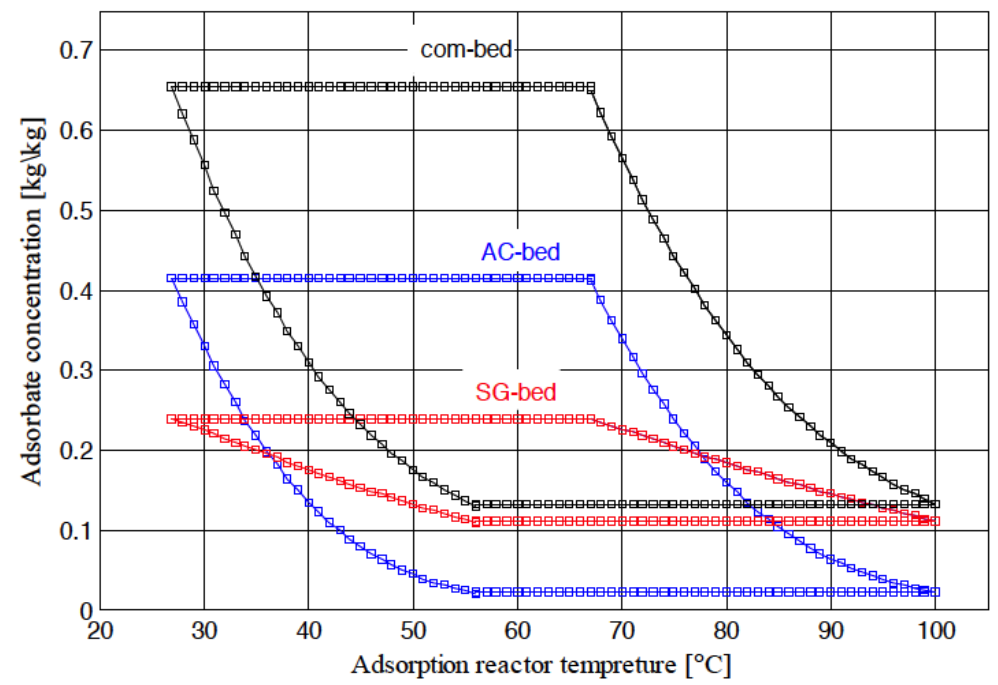

Figure 7: Variation of the adsorbate concentration with temperature along the cycle processes.

process at same temperature of about $67^{\circ} \mathrm{C}$. Then the reactor pressure remains steady during the generation process till the maximum cycle temperature $100{ }^{\circ} \mathrm{C}$ is approached. Both of the adsorbents start the desorption process at same temperature of $67^{\circ} \mathrm{C}$ and begin the adsorption process at same adsorption temperature of about $57^{\circ} \mathrm{C}$.

\subsection{Adsorption Uptake Profile}

The Figure 7 illustrates the variation of the adsorbate phase (methanol) concentration ratio with the temperature of the both sorption elements along the cycle. From this plot, the adsorbate concentration ratio $X_{\mathrm{SG}}$ of silica gel adsorption bed varies between its maximum value of $0.24 \mathrm{~kg}_{\text {meth }} / \mathrm{kg}_{\mathrm{sg}}$ its minimum value of $0.11 \mathrm{~kg}_{\text {meth }} / \mathrm{kg}_{\mathrm{sg}}$ during the cycle and the adsorbate concentration ratio of activated carbon adsorption bed
$\mathrm{X}_{\mathrm{AC}}$ varies between its maximum value of $0.42 \mathrm{~kg}_{\text {meth }} /$ $\mathrm{kg}_{\mathrm{AC}}$ to its minimum value of $0.021 \mathrm{~kg}_{\text {meth }} / \mathrm{kg}_{\mathrm{AC}}$ during the cycle.

This technique aims to increase the methanol concentration ratio $X\left[\mathrm{~kg}_{\text {meth }} / \mathrm{kg}_{\text {ads }}\right]$ inside the comadsorption reactor. Therefore, the adsorption reactor is filled by two different adsorbents. As a result of using this technique (com-reactor) we can note that the concentration ratio of methanol in adsorption reactor has been increased under the same hot water inlet temperature to maximum value of 0.66 , which has important effect on the system performance COP.

The variation of the methanol concentration inside the SG- particles and AC- particles, which are packed together in the com-adsorption reactor, is demonstrated for all of the working processes along duration of three consecutive cycles in Figure 8.

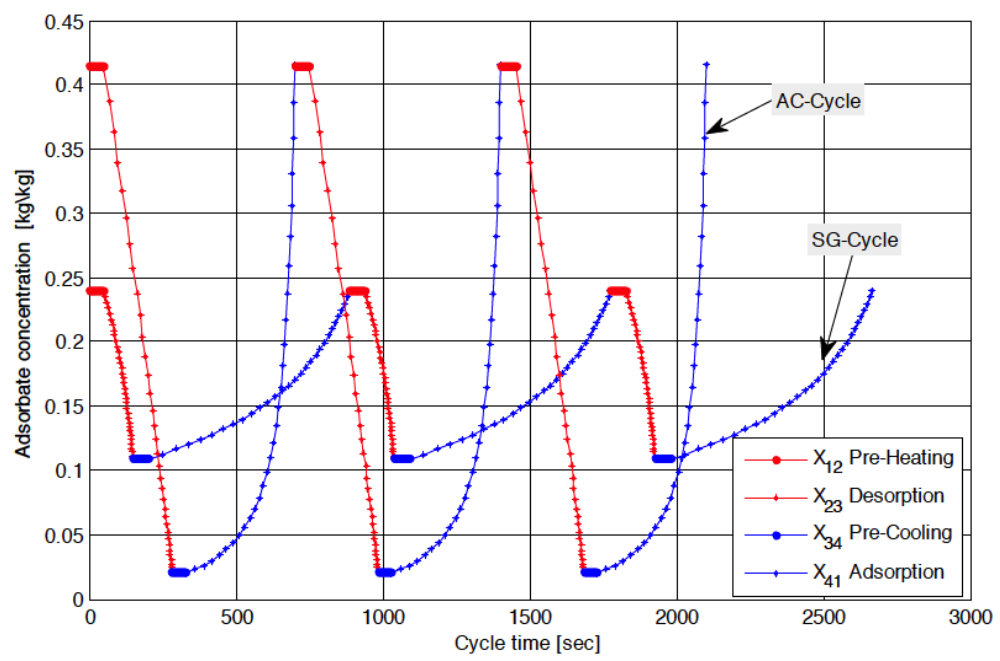

Figure 8: Variation of the adsorbate concentration along duration of three consecutive cycles. 
Table 5: The Required Time for All the Cycle Processes

\begin{tabular}{|l|c|c|c|c|c|}
\hline & Preheating & Desorption & Precooling & Adsorption & Total Cycle Time \\
\hline \hline Silica Gel & $46 \mathrm{sec}$ & $100 \mathrm{sec}$ & $52 \mathrm{sec}$ & $687 \mathrm{sec}$ & $885 \mathrm{sec}$ \\
\hline $\begin{array}{c}\text { Activated } \\
\text { Carbon }\end{array}$ & $50 \mathrm{sec}$ & $232 \mathrm{sec}$ & $46 \mathrm{sec}$ & $370 \mathrm{sec}$ & $698 \mathrm{sec}$ \\
\hline
\end{tabular}

Based on the properties of the adsorbents and calculations Eq.1 and Eq. 2 it is found, that the maximum adsorbate concentration of Activated carbon $\mathrm{X}_{\max }^{\mathrm{AC}}$ is considerably larger by half than that of Silica gel $\mathrm{X}_{\max }^{\mathrm{SG}}$ at the same ambient temperature $\mathrm{T}_{\mathrm{amb}}$ and the same evaporator pressure $P_{\text {evap }}$. Hence it has the potential to provide higher refrigeration effect. Because of the large value of the methanol concentration by the AC-particles compared with the methanol concentration by the SG-particles, the desorption process inside the AC- bed takes more time until the end of desorption process under the same desorption temperature of $100{ }^{\circ} \mathrm{C}$. Table 5 shows the required time of the cycle processes for both the SG- bed and AC- bed inside the com- adsorption reactor.

Because of the speed adsorption the AC-adsorber reach in equilibrium value of adsorption capacity faster than the SG-adsorber. This is because of the minimum adsorbate concentration of silica gel $\mathrm{X}_{\min }^{\mathrm{SG}}$, which is bigger by 6 times than the minimum adsorbate concentration of Activated carbon $\mathrm{X}_{\min }^{\mathrm{AC}}$ at the same highest cycle temperature of $100{ }^{\circ} \mathrm{C}$. That means the amount of refrigerant (methanol) inside the SGparticles at the start of the adsorption process is large. Therefore, the cooling water supplied to the SG-bed takes more time about $687 \mathrm{sec}$ during adsorption process until the SG particles can be adsorb the methanol vapor and reach at the equilibrium adsorption capacity $\mathrm{X}_{\max }^{\mathrm{SG}}$ of $0.24 \mathrm{~kg}_{\mathrm{meth}} / \mathrm{kg}$ sG.

\subsection{Evaluation of the Adsorbate (Refrigerant) Mass}

\subsubsection{Variation of the Desorbed Refrigerant Mass}

Figure 9 presents the evolution of the adsorbate mass inside the com-adsorption reactor with the adsorption reactor temperature for all of the working processes.

During the isobaric heating process, the mass of the adsorbate phase (methanol) in the SG-particles $\mathrm{M}_{\mathrm{a}}^{\mathrm{SG}}$ and in the AC-particles $\mathrm{M}_{\mathrm{a}}^{\mathrm{AC}}$ are continuously decreasing since the refrigerant is being freed from the com-adsorption reactor and flows towards the condenser, and the mass of the refrigerant vapor phase is varying during this process, because the concentration ratio is continuously decreasing along the process.

During the isobaric cooling process, the mass of the adsorbate phase in the $\mathrm{SG}$ adsorbent $\mathrm{M}_{\mathrm{a}}^{\mathrm{SG}}$ and in the $\mathrm{AC}$ adsorbent $\mathrm{M}_{\mathrm{a}}^{\mathrm{AC}}$ are continuously increasing, because the refrigerant leaves from the evaporator and flows into the com-adsorption reactor. Hence, the concentration ratio is continuously increasing along this process.

As noticed from the Figure 9, the adsorbate mass is continuously varying throughout the cycle operation. No changes of the adsorbate refrigerant mass are

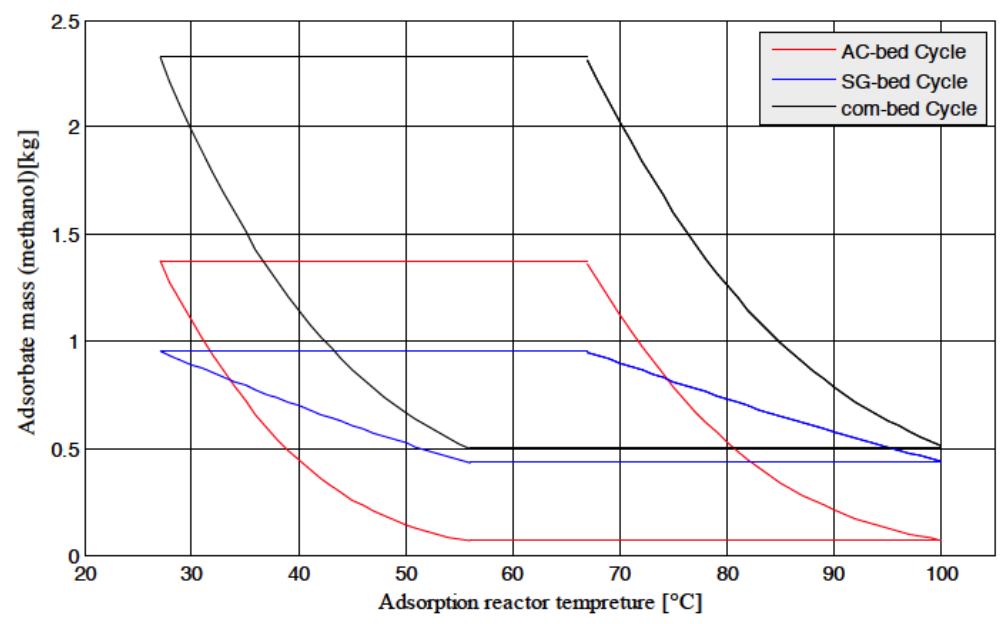

Figure 9: Variation of the adsorbate mass with adsorption reactor temperature along the cycle. 
observed during both of the isosteric processes (preheating and precooling). In the isobaric desorption phase, the desorbed methanol mass increases with temperature due to the decrease in refrigerant density with increasing temperature.

Using the com-AIP system with two absorption materials will increase the adsorbate mass content $\mathrm{m}_{\text {meth }}$ inside the adsorption reactor. Consequently the desorbed mass of methanol $\mathrm{m}_{\text {des}}$, that leaves the comreactor and flows towards the condenser, is higher than this mass $m_{\text {des }}$ when only silica gel or only activated carbon is used in the adsorption reactor. There for the mass flow rate of refrigerant $\dot{\mathrm{m}}_{\text {ref }}$ through the condenser and the evaporator increases and this has important effect on the refrigeration energy $Q_{e}$.

The adsorbate mass of silica gel adsorption bed attains its minimum cyclic value at the end of the desorption process about $0.44 \mathrm{~kg}$ whereas, the decreasing trend in the adsorbate mass during the isobaric adsorption process is obtained due to the increase in its density with the decreasing temperature. It attains its highest value at the end of adsorption process about $0.952 \mathrm{~kg}$. For the activated carbon adsorption reactor varies between its maximum value of $1.4 \mathrm{~kg}$ to its minimum value of $0.0712 \mathrm{~kg}$ during the cycle.

The development of the total desorbed mass with the desorption temperature from the com-adsorption reactor (from both the SG-particles and AC- particles) along the cycle is demonstrated in Figure 10.

It can be seen that the maximum desorbed mass from the SG-bed and from AC-bed equal to $0.52 \mathrm{~kg}$ and $1.33 \mathrm{~kg}$, respectively. As a result, the total refrigerant mass which is circulated through the comAIP system increases to $1.85 \mathrm{~kg}$.

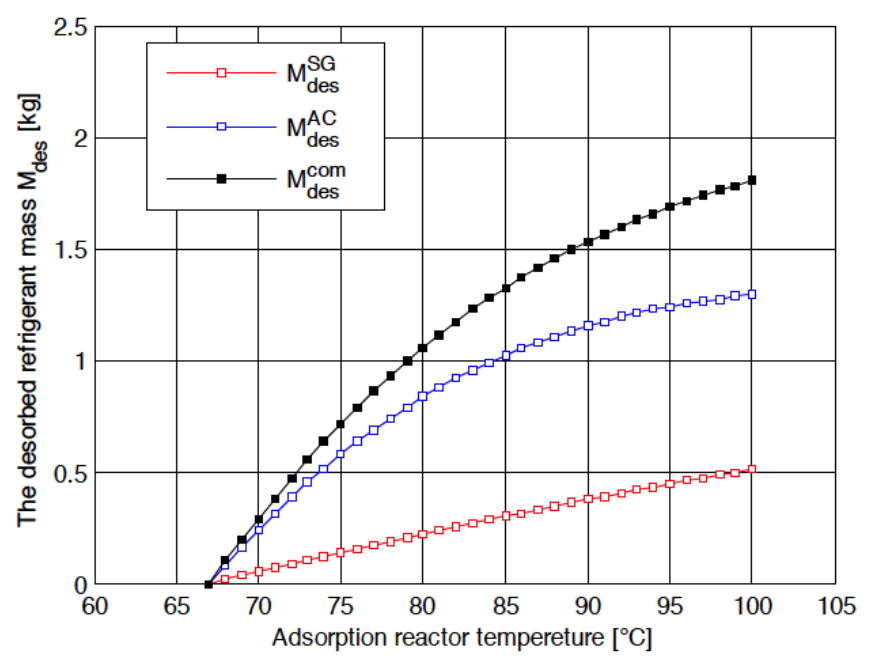

Figure 10: Evaluation of the desorbed refrigerant mass that leaves the SG-particles, AC-particles and the com-adsorption react or during isobaric desorption processes.

Figure 11 presents the evolution of the total refrigerant desorbed mass from the com-adsorption reactor along the cycle time of the desorption process.

It is noticed that the rate of the generated refrigerant has its minimum value at the beginning of the desorption process, when the bed temperature reaches the value of the generation temperature at $67^{\circ} \mathrm{C}$. This rate, as depicted in the figure, is continuously increasing with the increase of the temperature and it reaches the maximum value at the end of the desorption process with the maximum cycle temperature and the minimum concentration. The total desorbed refrigerant vapor mass at the end of this process equals $1.85 \mathrm{~kg}_{\text {meth }}$.

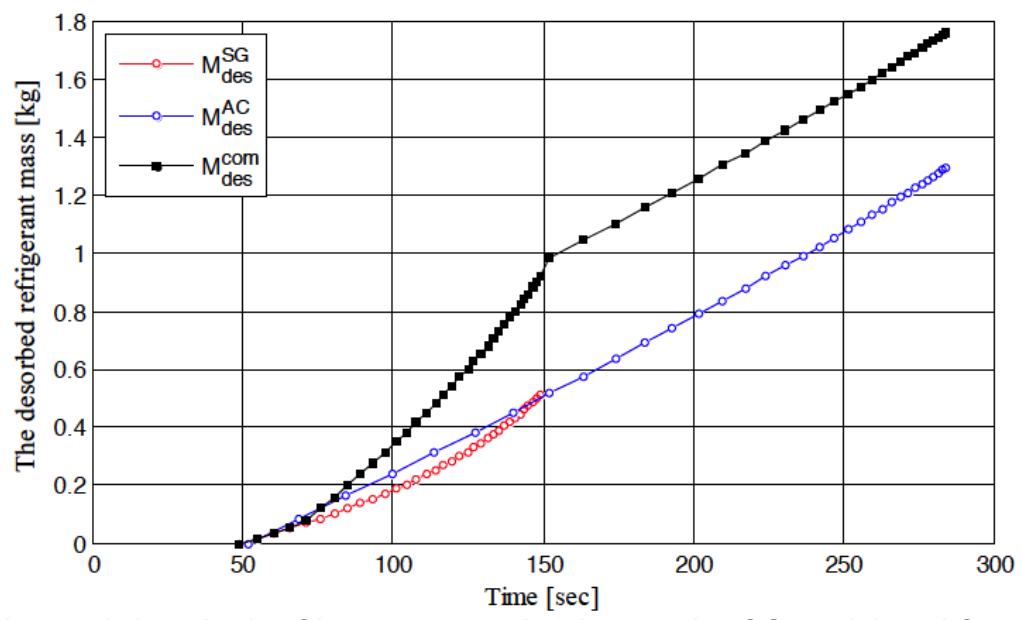

Figure 11: Evaluation of the total desorbed refrigerant mass that leaves the SG-particles, AC-particles and com-adsorption reactor along the time of the desorption process. 
Based on the simulation results, it found that the SG-bed reaches the end of desorption process faster than AC-bed. This has a significant impact on saving the input energy required from driving heat source and the system could produce ice before the end of desorption process inside the AC-bed.

As a result of using this technique, it is found that the refrigerant desorbed mass, that leaves from adsorption reactor into the condenser, has been increased to high value, which has important effect on the mass flow rate circulated through the condenser and the evaporator. This improved the COP and increased the mass of ice produced from the com-AIM system.

\subsubsection{Variation of the Adsorbed Refrigerant Mass}

Figure 12 shows the effect of the adsorption reactor temperature on the amount of adsorbed refrigerant $\mathrm{m}_{\mathrm{ads}}$ during isobaric adsorption process. The adsorbate concentration ratio increases with cooling of the comadsorption reactor, which means a larger amount of methanol, can be adsorbed with decreasing adsorption temperature during the adsorption process. It achieves a maximal value under initial temperature of $27^{\circ} \mathrm{C}$ with SG-bed cycle of about $0.52 \mathrm{~kg}_{\text {meth }}$, and $1.33 \mathrm{~kg}_{\text {meth }}$ with AC-bed cycle. As a result the total amount of methanol, adsorbed with this proposed technique, achieves a value of $1.85 \mathrm{~kg}_{\text {meth }}$ at the end position of adsorption process under ambient temperature of $27^{\circ} \mathrm{C}$ and evaporation pressure of $3.31 \mathrm{kPa}$.

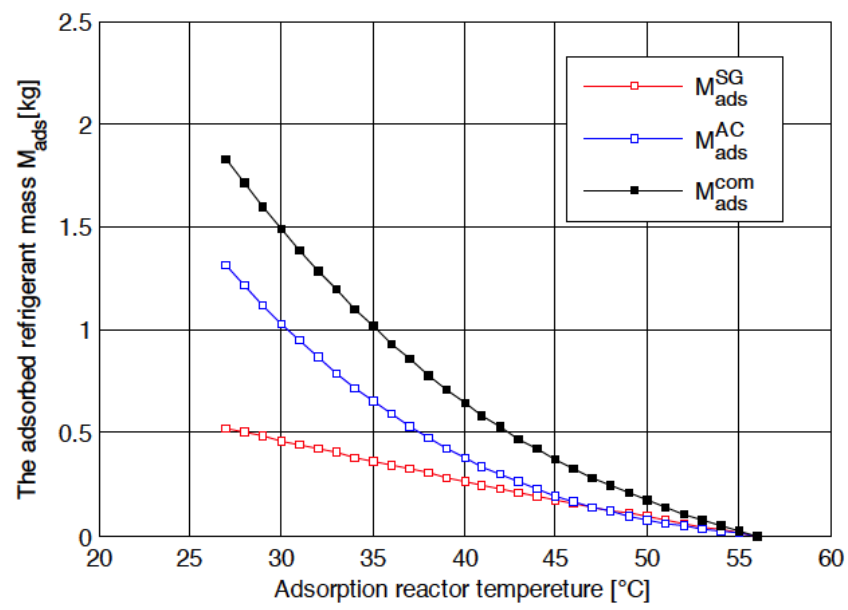

Figure 12: Evaluation of the adsorbed refrigerant mass that flows toward the SG-particles, AC-particle sand the comadsorption reactor during the isobaric adsorption processes.

The adsorbed refrigerant mass evolution with the cycle time during isobaric adsorption processes is demonstrated in Figure 13. The adsorbed amount of methanol significantly rises with decreasing the adsorption reactor temperature along the duration of adsorption process. Based on the simulation results and properties of the sorption materials, it was found that the adsorption process inside SG-bed takes more time than the same process inside the $\mathrm{AC}$-bed.

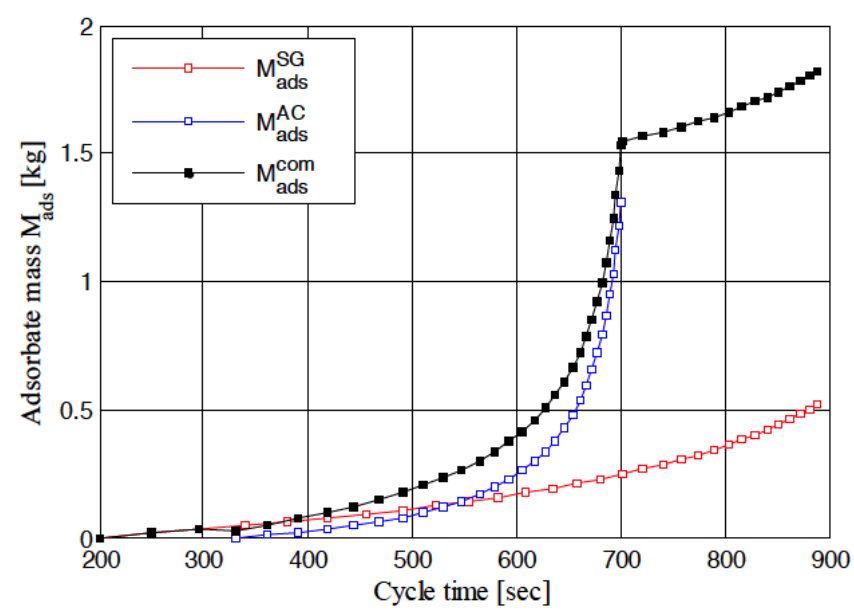

Figure 13: Evaluation of the desorbed refrigerant mass that leaves the SG-particles, AC-particles and the com-adsorption reactor along the time of the adsorption process.

This is because the amount of refrigerant (methanol) inside the SG-particles at start of the adsorption process is larger than this amount inside the AC-particles. Therefore, the duration of supplying with the cooling water to the SG-bed is about $687 \mathrm{sec}$ during adsorption process until the SG particles can adsorb the methanol vapor and reach at the equilibrium adsorption capacity $X_{\max }^{S G}$. Because the time of adsorption process is different for SG-bed and AC-bed, this technique could work nearly as permanent system in order to produce the ice.

\subsubsection{The Amount of Produced Ice and the Refrigeration Energy}

The Figure 14 shows the effect of desorption temperature on the ice production $\mathrm{m}_{\text {ice. }}$. The trend shows considerable increasing in $m_{\text {ice }}$ with increasing desorption temperature over the range shown from $67^{\circ} \mathrm{C}$ to $100{ }^{\circ} \mathrm{C}$. It can be seen also that the larger fraction from the produced ice about $72 \%$ is produced from the AC-particles whereas the remaining part of the total amount ice produced $28 \%$ is created from the SGparticles. This is because of the large adsorption quantity of the activated carbon particles compared to silica gel as adsorbent.

The Eq. 63 shows that the ice produced is proportional to the refrigeration energy. The effect of desorption temperature on the refrigeration energy of the system is shown in the Figure 15. 


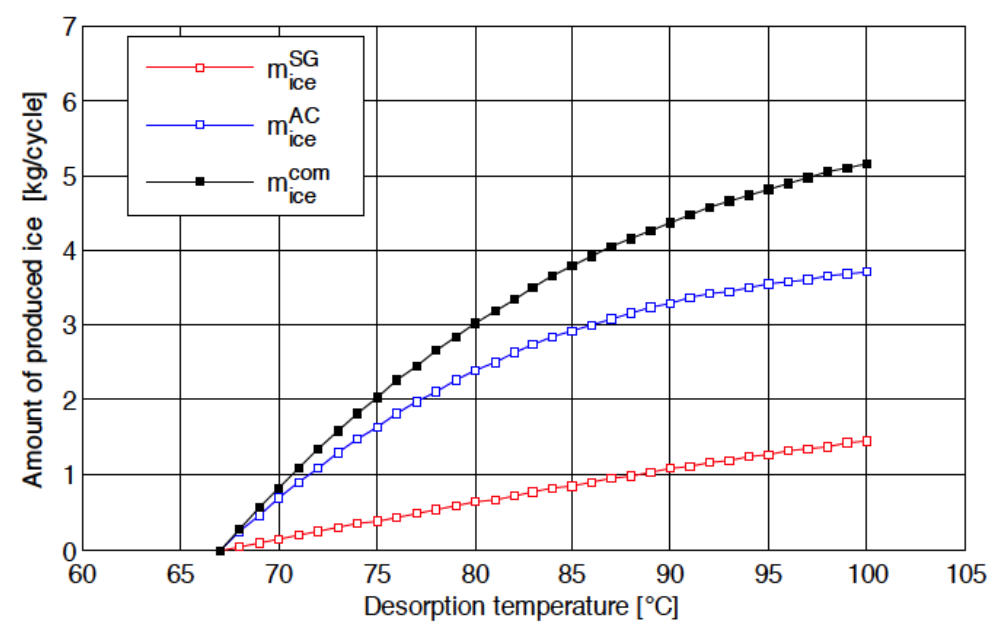

Figure 14: Effect of the desorption temperature on the amount of produced ice.

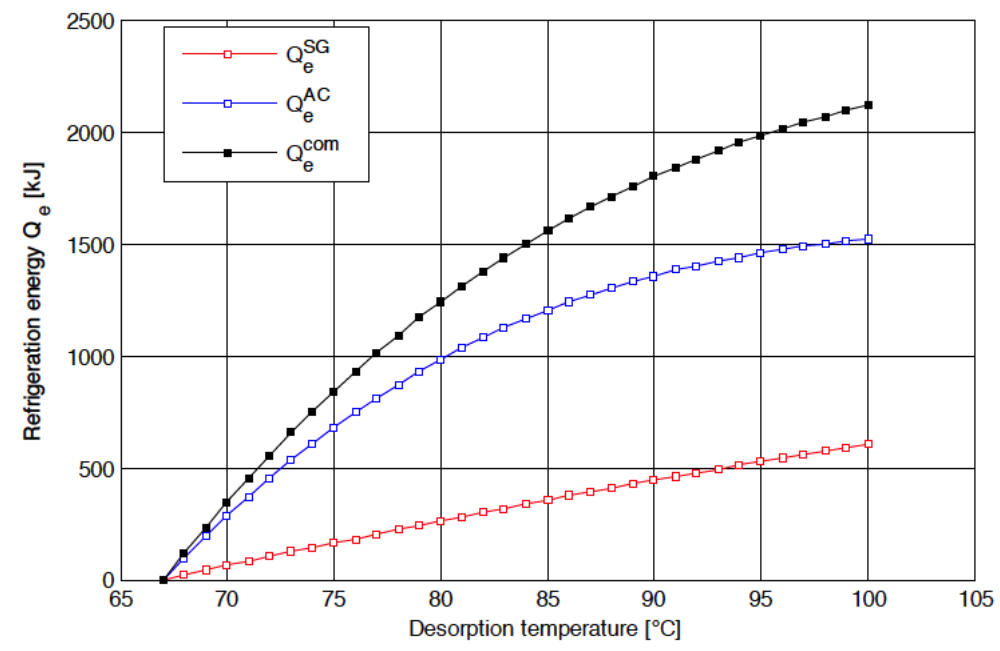

Figure 15: Variation of the cooling energy with the desorption temperature.

When desorption temperature increases, the refrigeration energy also increases. Based on simulation results and physical properties of adsorbents it was found that the cycled refrigerant mass $m_{\text {sorbent }}\left(X_{\max }-X_{\min }\right)$ increases with higher desorption temperature. Thus an increase in $m_{\text {ref }}$ will result in improvement of the refrigeration energy.

\subsection{Evaluation of Com- Adsorption Ice Production AIP System}

In order to assess the effectiveness of com- AIM system proposed on the driving energy required from external heat source $Q_{i n}$, a comparison with two AIP systems is made under the same operating conditions, taking into account the refrigeration capacity $Q_{e}$ and performance COP. The first system works using activated carbon-methanol and the second works using silica gel-methanol as working pair. The modeling of both the two systems has been simulated also using a MATLAB program.

As shown in the Figure 16 the added energy $Q_{i n}$, which is introduced to the com-, SG- and ACadsorption reactor of these three systems is demonstrated versus the adsorption reactor temperature. The total amount of the required input energy to activate the silica gel adsorption reactor is estimated to $2796 \mathrm{~kJ}$ per cycle and to $4460 \mathrm{~kJ}$ for activated carbon adsorption reactor.

In comparison with the SG-bed and the AC-bed, we can notice that the driving energy required to activate the novel strategy of com-adsorption reactor is smaller than the required energy in AC-bed and is estimated to be $3628 \mathrm{~kJ}$, and thus it is bigger than the required energy in SG-system but the com-adsorption reactor can produce the double amount of ice under the same 


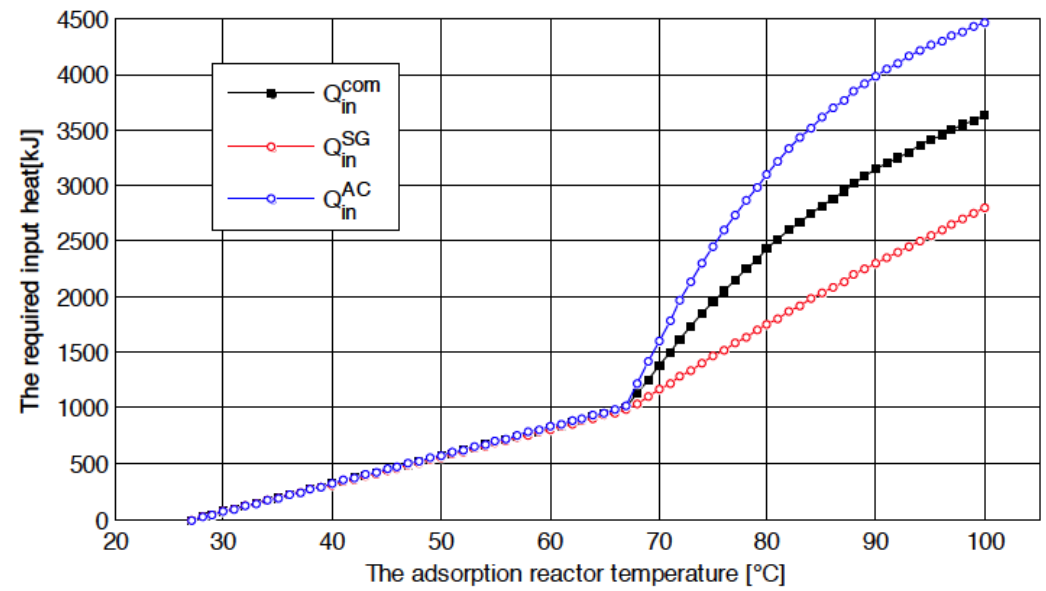

Figure 16: The driving energy added to the SG-bed, AC-bed and com-bed during the isosteric preheating and isobaric desorption processes.

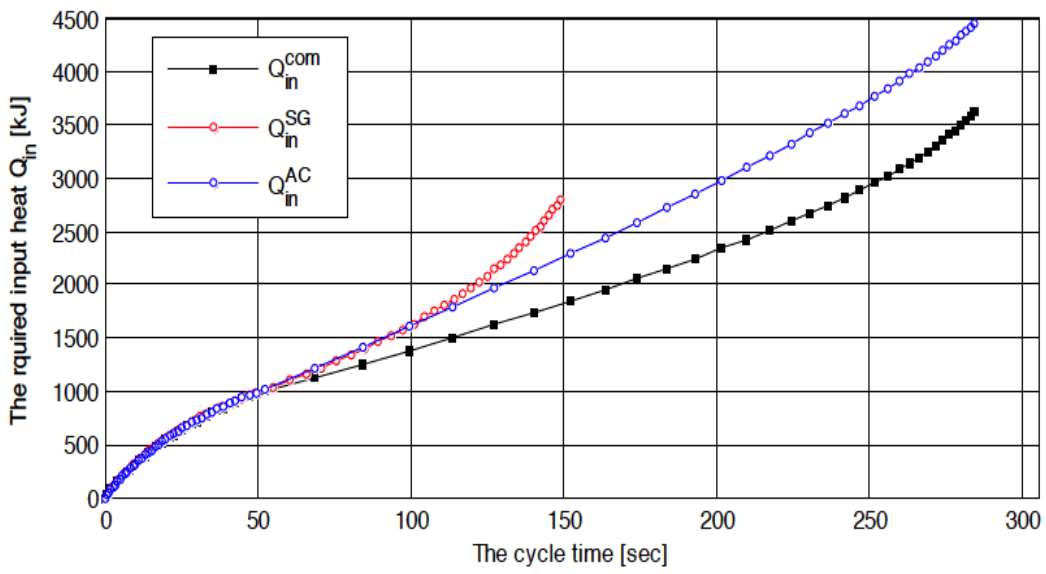

Figure 17: The driving energy added to the SG-bed, AC-bed and com-bed during the cycle time.

operating conditions. It is interesting to notice from the Figure 18 how the driving energy varies with respect to the duration of isosteric and isobaric heating processes over the same range $\left(67-100^{\circ} \mathrm{C}\right)$.

As seen in the Figure 17 both the com-bed and ACbed take the same desorption time to heat up and activate the adsorption reactor, but the com-bed adsorption reactor has an advantage compared with the AC-bed that its required driving energy is smaller than the required energy of AC-system. The SG-bed takes about $150 \mathrm{sec}$ to desorb the refrigerant toward the condenser, whereas the com-bed takes about $287 \mathrm{sec}$ to desorb the refrigerant. But the SG-bed adsorption reactor has a disadvantage that it needs higher driving energy during its smaller desorption time compared to com-bed and AC-bed.

As a result of the using this technique we notice that the required energy has been saved, which has an important effect on the selection of energy source.
A fraction from this energy about $1000 \mathrm{~kJ}$ is needed to bring the adsorption reactor up to the starting desorption with temperature of $67^{\circ} \mathrm{C}$.

As noticed from the plot in Figure 16, the temperature increases rapidly with respect to the driving energy during the preheating process in comparison with the desorption process. The reason is that all of the energy input to the adsorption bed during the pre-heating process is consumed only in the sensible heating of the bed, whereas, in desorption process, a large portion of energy is consumed during the refrigerant generation process.

Figure 18 shows the influence of adsorption reactor temperature on the system COP for the SG-, AC- and com-AIP system. It is seen that COP increases as the adsorption reactor temperature is increased from 67 to $100{ }^{\circ} \mathrm{C}$. This is because the amount of refrigerant (methanol) circulated increases, due to increased refrigerant desorption with higher driving source 


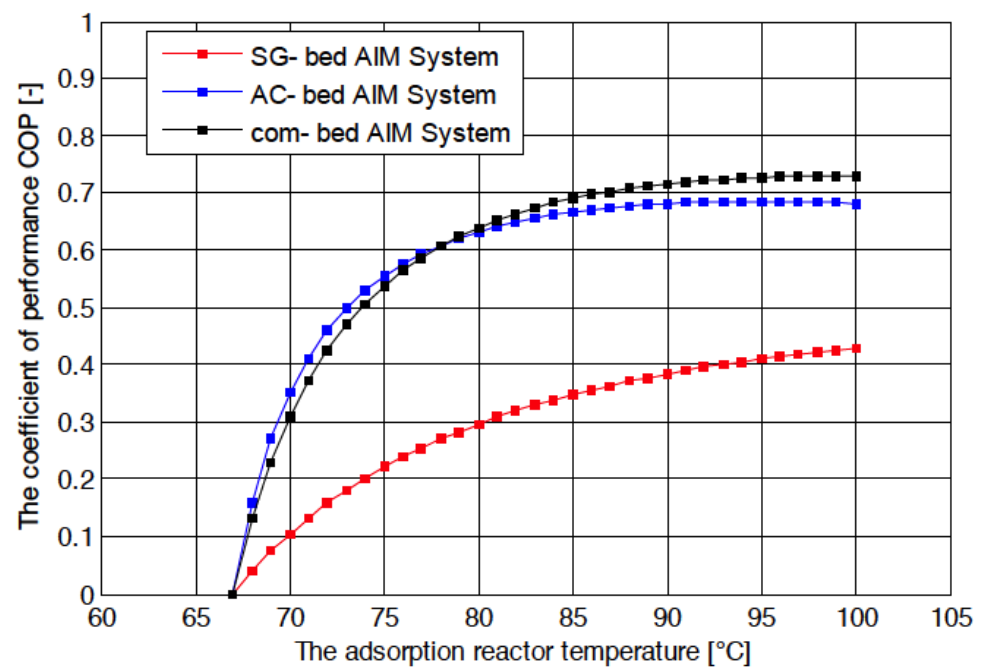

Figure 18: Effect of the adsorption reactor temperature on the coefficient of performance COP for the three AIM systems.

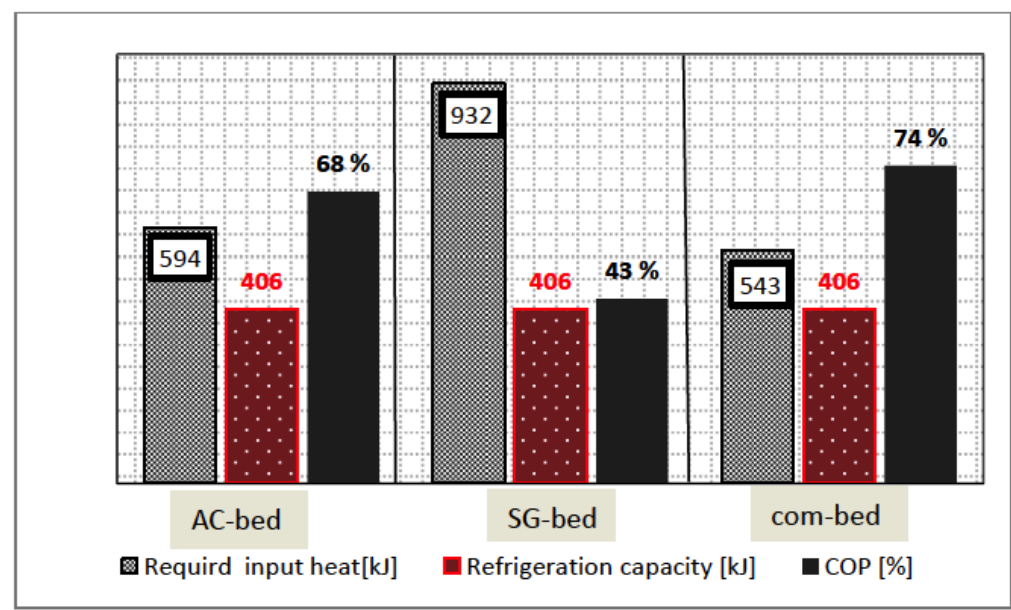

Figure 19: Comparison between the three AIP systems, the first is filled only by silica gel- methanol, the second is filled only by activated carbon-methanol and the third is filled by combined adsorbents by silica gel/activated carbon- methanol.

temperature. The COP remains almost steady for large values of $\mathrm{Tb}>90^{\circ} \mathrm{C}$. This linear slight increase happens due to the fact that most of the methanol had desorbed below $90{ }^{\circ} \mathrm{C}$, so the increase in heat input produces negligible methanol and hence the COP remains constant.

Based on the comparison with the silica gelmethanol AIP system the simulation results showed that, the COP of this novel com-AIM system was improved by $40 \%$ and with activated carbon-methanol AIP system was improved by $7 \%$ when the temperature of hot water inlet, cooling water inlet, chilled water inlet and the ice produced were $100{ }^{\circ} \mathrm{C}, 24^{\circ} \mathrm{C}, 15^{\circ} \mathrm{C}$ and $-3{ }^{\circ} \mathrm{C}$ respectively. This is because the heating energy from the driving heat source could be saved by $20 \%$. Due to a lower specific heat capacity $C_{p}$ of the silica gel particles, smaller density of activated carbon and higher adsorption quantity of the activated carbon particles, the com-adsorption reactor has a higher COP and lower heat input $Q_{\text {in }}$ compared to SG-bed and AC-bed.

Table 6: Standard Operating Conditions

\begin{tabular}{|c|c|c|}
\hline Parameter & Value & Unit \\
\hline Hot water inlet temperature & 100 & {$\left[{ }^{\circ} \mathrm{C}\right]$} \\
\hline Hot water inlet flow rate & 0.232 & Kg.sec ${ }^{-1}$ \\
\hline Cooling water inlet temperature & 24 & {$\left[{ }^{\circ} \mathrm{C}\right]$} \\
\hline Cooling water inlet flow rate & 0.4 & $\mathrm{Kg} \cdot \mathrm{sec}^{-1}$ \\
\hline Chilled water inlet temperature & 15 & {$\left[{ }^{\circ} \mathrm{C}\right]$} \\
\hline
\end{tabular}

The comparison with two AIP systems is made under the same operating conditions. The inlet temperature of the heat transfer fluid are $100{ }^{\circ} \mathrm{C}$ for hot 
water, $24{ }^{\circ} \mathrm{C}$ for cooling water, and $15{ }^{\circ} \mathrm{C}$ for chilled water. The standard operating conditions are shown in Table 6.

As shown in Figure 19, the refrigeration energy $Q_{\mathrm{e}}$, needed for producing $1 \mathrm{~kg}$ of ice, are similar for all three systems. But the driving energy required by the com-heat exchanger is about $543 \mathrm{~kJ}$ per cycle and the performance of the system COP reaches $73 \%$. Based on the simulation results and the comparison with the AC-AIP system and with SG-AIP system, it has been found that the required input heat by $A C$-bed is $549 \mathrm{~kJ}$ and by SG-bed is $932 \mathrm{~kJ}$ under the same operating conditions. This mean that the $Q_{\text {in }}$ input heat required from the external heat source of this novel com-heat exchanger could be saved by $40 \%$ compared with silica gel-methanol AIP system and by $6 \%$ compared with activated carbon-methanol AIP system when the operating conditions were similar.

Consequently the com-adsorption reactor has an important advantage that can save the heat, required by the heat source and have efficient performance.

\section{SUMMARY AND CONCLUSIONS}

This work was done to improve their frigeration capacity and save the driving energy. To achieve that, a novel com-bed AIP system with both silica gel and activated carbon as adsorbents and methanol as refrigerant theoretically and thermo dynamically is investigated. The analytical model is simulated using MATLAB software.

The performance of this technique and the needed driving energy are evaluated by comparing with two AIP systems, the first system works using silica $\mathrm{gel} / \mathrm{methanol}$ and the second works using activated carbon/methanol as workings pair. The boundary conditions used were similar between the three systems.

This com-AIP system can utilize the fluctuated heat source temperature between 65 and $100{ }^{\circ} \mathrm{C}$ to produce effective cold (ice) along with a coolant inlet $15^{\circ} \mathrm{C}$. The main feature of the proposed AIM system is the ability to be driven by relatively low temperature heat source. Simulation results showed that the combined heat exchanger could save up input energy from heat source about $40 \%$. The analysis of the cooling processes and adsorption/desorption processes for com-adsorption reactor theoretical were studied by using $3.9 \mathrm{~kg}$ of silica gel, $3 \mathrm{~kg}$ of activated carbon and 4 $\mathrm{kg}$ of methanol.
The simulation results showed that $5.34 \mathrm{~kg}$ of ice per cycle could be obtained with a COP equals 0.74 under the hot water inlet temperature of $100{ }^{\circ} \mathrm{C}$ whereas the evaporation temperature of $-3{ }^{\circ} \mathrm{C}$. This amount of ice produced decreases to $4 \mathrm{~kg}$ with using only silica gel in the adsorption reactor and increases to about $7 \mathrm{~kg}$, if the adsorption reactor is filled with only activated carbon as adsorbent, but in this case the required heat input is about $20 \%$ higher.

In the cycle simulation study, the desorption temperature and the mass flow rate of refrigerant $\dot{\mathrm{m}}_{\text {ref }}$ are the most influential parameters. COP increases with the increase of desorption temperature and refrigeration energy increases with the increase of the mass flow rate of refrigerant $\dot{\mathrm{m}}_{\text {ref }}$. Highest COP value is obtained for hot water temperature variation from 90 to $100{ }^{\circ} \mathrm{C}$. In the low heat source temperature, COP has been improved significantly.

The comparison with SG-AIP system showed that COP of the combined heat exchanger was improved by $40 \%$. Moreover, simulation results showed that flow rate of refrigerant has a big influence on the amount of ice produced.

\section{ACKNOWLEDGEMENTS}

The authors wish to thank the Ilmenau University (Ilmenau-Germany), HochschuleOstwestfalen-Lippe (Höxter-Germany) and AL-Baath University (Syria) for the financial support on this study. I would also like to thank great Prof. Dr. Ing Habil. Christian Karcher for some discussions.

\section{NOMENCLATURE}

\begin{tabular}{|c|c|c|}
\hline Symbol & SI Unit & \\
\hline A & {$\left[\mathrm{m}^{2}\right]$} & Heat transfer area \\
\hline COP & {$[-]$} & Coefficient of performance \\
\hline$C_{p}$ & {$[\mathrm{~kJ} / \mathrm{kg} . \mathrm{K}]$} & $\begin{array}{l}\text { Specific heat capacity at } \\
\text { constant pressure }\end{array}$ \\
\hline $\mathrm{C}_{\mathrm{v}}$ & {$[\mathrm{kJ} / \mathrm{kg} . \mathrm{K}]$} & $\begin{array}{l}\text { Specific heat capacity at } \\
\text { constant volume }\end{array}$ \\
\hline $\mathrm{C}_{\text {ice }}$ & {$[\mathrm{kJ} / \mathrm{kg} . \mathrm{K}]$} & Ice specific heat capacity \\
\hline$D_{0}$ & {$\left[\mathrm{~m}^{2} / \mathrm{sec}\right]$} & Surface diffusion coefficient \\
\hline$E_{a}$ & {$[\mathrm{~kJ} / \mathrm{kg}]$} & $\begin{array}{l}\text { Activation energy of } \\
\text { Surface diffusion }\end{array}$ \\
\hline h & {$[\mathrm{kJ} / \mathrm{kg}]$} & Specific enthalpy \\
\hline
\end{tabular}




\begin{tabular}{|c|c|c|}
\hline$\Delta \mathrm{H}_{\text {cond }}$ & {$[\mathrm{kJ} / \mathrm{kg}]$} & $\begin{array}{l}\text { The latent energy of } \\
\text { condensation }\end{array}$ \\
\hline$L_{e}$ & {$[\mathrm{~kJ} / \mathrm{kg}]$} & $\begin{array}{l}\text { The latent energy of } \\
\text { vaporization }\end{array}$ \\
\hline$L_{f}$ & {$[\mathrm{~kJ} / \mathrm{kg}]$} & Latent heat of ice fusion \\
\hline $\mathrm{M} / \mathrm{m}$ & {$[\mathrm{kg}]$} & Mass \\
\hline$\dot{\mathrm{m}}$ & {$[\mathrm{kg} / \mathrm{sec}]$} & Mass flow rate \\
\hline$P$ & {$[\mathrm{kPa}]$} & System pressure \\
\hline Q & {$[\mathrm{kJ}]$} & Heat amount \\
\hline$\dot{\mathrm{Q}}$ & {$[\mathrm{kW}]$} & Heat rate \\
\hline$Q_{e}$ & {$[\mathrm{~kJ}]$} & Refrigeration capacity \\
\hline $\mathrm{R}$ & {$[\mathrm{kJ} / \mathrm{kg} . \mathrm{K}]$} & Universal gas constant \\
\hline$r_{p}$ & {$[\mathrm{~m}]$} & Particle radius \\
\hline $\mathrm{T}$ & {$\left[{ }^{\circ} \mathrm{C}\right]$} & Temperature \\
\hline $\mathrm{T}$ & {$[\mathrm{sec}]$} & Time \\
\hline $\mathrm{u}_{\mathrm{a}}$ & {$[\mathrm{kJ} / \mathrm{kg}]$} & The specific internal energy \\
\hline $\mathrm{U}_{\mathrm{a}}$ & {$[\mathrm{kJ}]$} & Total internal energy \\
\hline$x$ & {$\left[\mathrm{~kg}_{\text {meth }} / \mathrm{kg}_{\mathrm{s}}\right]$} & $\begin{array}{l}\text { Uptake value of adsorbate } \\
\text { (concentration) }\end{array}$ \\
\hline $\mathrm{X}_{0}$ & {$\left[\mathrm{~kg}_{\text {meth }} / \mathrm{kg}_{\mathrm{s}}\right]$} & $\begin{array}{l}\text { Maximum limit of mass } \\
\text { adsorbed }\end{array}$ \\
\hline $\begin{array}{l}\mathrm{D}, \mathrm{K} \text { and } \\
\mathrm{n}\end{array}$ & {$[-]$} & Dubinin-Astakhov constants \\
\hline B & {$[-]$} & $\begin{array}{l}\text { Porosity of the solid } \\
\text { adsorbent medium }\end{array}$ \\
\hline 7 & {$[-]$} & Dryness fraction of steam \\
\hline
\end{tabular}

\section{SUBSCRIPTS}

h Hot water to adsorption reactor

ca Cooling water to adsorption reactor

c Cooling water to condenser

ch Chilled water to evaporator

evap Evaporator

cond Condenser

b Bed/ Heat exchanger / Adsorber / desorber

\begin{tabular}{|c|c|}
\hline SG & Silica gel \\
\hline$A C$ & Activated carbon \\
\hline des & Desorption/Desorber \\
\hline ads & Adsorption/Adsorber \\
\hline add & Added \\
\hline in & Inlet \\
\hline & Outlet \\
\hline re & Refrigerant \\
\hline rej & Rejected \\
\hline sat & Saturation \\
\hline$f$ & Fin \\
\hline $\mathrm{mc}$ & Metallic components of the generator \\
\hline s & Sorption material \\
\hline a & Adsorbate phase of methanol \\
\hline $\mathrm{v}$ & Vapor phase of methanol \\
\hline amb & Ambient or atmospheric \\
\hline eq & Equilibrium \\
\hline meth & Methanol \\
\hline $\max$ & Maximum \\
\hline $\min$ & Minimum \\
\hline ice & Ice \\
\hline com & Combined \\
\hline AIP & Adsorption Ice Production \\
\hline $\mathrm{cu}$ & Copper \\
\hline al & Aluminum \\
\hline$t$ & Tube \\
\hline
\end{tabular}

[1] Ahmad RMR. Theoretical and experimental investigation of silica gel-water adsorption refrigeration systems 2012.

[2] Wang S. Hand book of air conditioning and refrigeration. $2^{\text {nd }}$ Edition. McGraw-Hill Professional 2000.

[3] Amir S and Majid B. Assessment of adsorber bed designs in waste-heat driven adsorption cooling system for vehicle air conditioning and refrigeration. Renewable and Sustainable Energy Reviews 2013; 30: 440-451.

[4] Douss $\mathrm{N}$ and Meunier F. Experimental study of cascading adsorption cycles. Chemical Engineering Science 1989; 
44(2): 225-235. http://dx.doi.org/10.1016/0009-2509(89)85060-2

[5] Gregg SJ and Sing KSW. Adsorption, surface area, and porosity. $2^{\text {nd }}$ Edition. Academic Press 1982.

[6] Chua HT, Ng KC, Malek A, Kashiwagi T, Akisawa A and Saha BB. Modeling the performance of two-bed silica Gelwater adsorption chillers. Int $\mathrm{J}$ Refrigeration 1999; 22: 194-204.

http://dx.doi.org/10.1016/S0140-7007(98)00063-2

[7] Chau HT, Ng KC, Malek A, Kashiwagi T, Akisawa A, Saha BB. Modeling the performance of two-bed, silica gel-water adsorption chillers. International Journal of Refrigeration 1999; 22: 194-204.

http://dx.doi.org/10.1016/S0140-7007(98)00063-2

[8] Boelman BC, Saha BB and Kashiwagi T. Experimental investigation of a silica gel-water adsorption refrigeration cycle the influence of operating conditions on cooling output and COP. ASHRAE Trans Res 1995; 101(2): 358-366.

[9] Oertel $\mathrm{K}$ and Fischer $\mathrm{M}$. Adsorption cooling system for cold storage using methanol/silicagel. Applied Thermal Engineering 1997; 18: 773-786. http://dx.doi.org/10.1016/S1359-4311(97)00107-5

[10] Wang DC, Xia ZZ and Wu JY. Design and performance prediction of a novel zeolite-water adsorption air conditioner. Energy Conversion and Mangement 2006; 47: 590-610. http://dx.doi.org/10.1016/j.enconman.2005.05.011

[11] Critoph RE. Forced convection adsorption cycles. Applied Thermal Engineering 1998; 18: 799-807. http://dx.doi.org/10.1016/S1359-4311(97)00110-5

[12] Anyanwu EE and Ezekwe Cl. Design, construction and test run of a solid adsorption solar Refrigerator using activated carbon/methanol as adsorbent/adsorbate pair. Energy Convers Manage 2003; 44: 2879-2892. http://dx.doi.org/10.1016/S0196-8904(03)00072-4

[13] Gong LX, Wang RZ, Xia ZZ and Lu ZS. Experimental study on an adsorption chiller employing lithium chloride in silica gel and methanol. International journal of refrigeration 2012; 35: 1950-1957. http://dx.doi.org/10.1016/j.ijrefrig.2012.06.013

[14] Hu P, Yao JJ and Chen ZS. Analysis for composite zeolite/ foam aluminum-water mass recovery adsorption refrigeration system driven by engine exhaust heat. Energy Convers. Manage 2009; 50: 255-261.

http://dx.doi.org/10.1016/j.enconman.2008.09.022

[15] Maggio G, Gordeeva LG, Freni A, Aristov, Yul, Santori G, Polonara F and Restuccia G. Simulation of a solid sorption ice-maker based on the novel composite sorbent (lithium chloride in silicagel pores). Appl Therm Eng 2012; 29: 1714-1720.

http://dx.doi.org/10.1016/j.applthermaleng.2008.07.026

[16] Wang LW, Wang RZ and Oliveira RG. A review on adsorption working pairs for refrigeration. Renew Sust Energy Rev 2009; 13(3): 518-534.

http://dx.doi.org/10.1016/j.rser.2007.12.002

[17] Srivastava NC and Eames IW. A review of adsorbents and adsorbates in solid-vapour adsorption heat pump systems. Applied Thermal Engineering 1998; 18: 707-714. http://dx.doi.org/10.1016/S1359-4311(97)00106-3

[18] El-Sharkawy II. Study on adsorption of methanol onto carbon based adsorbents. International journal of refrigeration 2009; 32: 1579-1586. http://dx.doi.org/10.1016/j.jirefrig.2009.06.011

[19] Farrington $\mathrm{R}$ and Rugh J. Impact of vehicle air-conditioning on fuel economy, tailpipe emissions and electric vehicle range. In: Proceeding of the Earth Technologies Forum, Washington, DC 2009.

[20] Hasan HZ. Energy analysis and performance evaluation of the adsorption refrigeration system 2013.

[21] Hasan HZ, Mohamad AA, Al yousef $Y$ and Al-Ansary HA. A review on the equation of state for the working pairs used in adsorption cooling systems. Renewable and Sustainable Energy Reviews 2015; 45: 600-608. http://dx.doi.org/10.1016/j.rser.2015.02.008

[22] Glueckauf E. Formulation for diffusion into spheres and their applications to chromatography. Trans Faraday Soc 1955; 51: 1540-1551.

http://dx.doi.org/10.1039/TF9555101540

[23] Sakoda A and Suzuki M. Fundamental study on solar powered adsorption cooling system. J Chem Eng Japan 1984; 17: 52.

http://dx.doi.org/10.1252/jcej.17.52

[24] Chua HT, Ng KC, Malek A, Kashiwage T, Akisawa A and Saha BB. Modeling the performance of two bed, silicagelwater adsorption chiller. International journal of refrigeration 1999; 22: 194-204.

http://dx.doi.org/10.1016/S0140-7007(98)00063-2

[25] Gnielinski V. New Equations for Heat and Mass Transfer in Turbulent Pipe and Channel Flow. Int Chem Eng 1976; 16: 359-368.

[26] Robert D Goodwin. Methanol Thermodynamic Properties from 176 to $673 \mathrm{~K}$ at pressures to 70 bar 1987 .

Received on 04-07-2016

DOI: http://dx.doi.org/10.15377/2409-5818.2016.03.01.1

(C) 2016 Ali and Ajib; Avanti Publishers.

This is an open access article licensed under the terms of the Creative Commons Attribution Non-Commercial License (http://creativecommons.org/licenses/by-nc/3.0/) which permits unrestricted, non-commercial use, distribution and reproduction in any medium, provided the work is properly cited. 